\title{
Radial Glial Cell-Neuron Interaction Directs Axon Formation at the Opposite Side of the Neuron from the Contact Site
}

\author{
Chundi Xu, Yasuhiro Funahashi, Takashi Watanabe, Tetsuya Takano, Shinichi Nakamuta, Takashi Namba, \\ and Kozo Kaibuchi \\ Department of Cell Pharmacology, Nagoya University Graduate School of Medicine, Showa, Nagoya 466-8550, Japan
}

How extracellular cues direct axon-dendrite polarization in mouse developing neurons is not fully understood. Here, we report that the radial glial cell (RGC)-cortical neuron interaction directs axon formation at the opposite side of the neuron from the contact site. $\mathrm{N}$-cadherin accumulates at the contact site between the RGC and cortical neuron. Inhibition of the N-cadherin-mediated adhesion decreases this oriented axon formation in vitro, and disrupts the axon-dendrite polarization in vivo. Furthermore, the RGC-neuron interaction induces the polarized distribution of active RhoA at the contacting neurite and active Racl at the opposite neurite. Inhibition of Rho-Rho-kinase signaling in a neuron impairs the oriented axon formation in vitro, and prevents axon-dendrite polarization in vivo. Collectively, these results suggest that the $\mathrm{N}$-cadherin-mediated radial glia-neuron interaction determines the contacting neurite as the leading process for radial glia-guided neuronal migration and directs axon formation to the opposite side acting through the Rho family GTPases.

Key words: axon formation; axon-dendrite polarization; cell-cell interaction; N-cadherin; radial glial cell; RhoA

\section{Significance Statement}

Neurons are highly polarized cell lines typically with a single axon and multiple dendrites, which underlies the ability of integrating and transmitting the information in the brain. How is the axon-dendrite polarity of neurons established in the developing neocortex? Here we show that the N-cadherin-mediated radial glial cell-neuron interaction directs axon-dendrite polarization, the radial glial cell-neuron interaction induces polarized distribution of active RhoA and active Racl in neurons, and Rho-Rhokinase signaling is required for axon-dendrite polarization. Our work advances the overall understanding of how extracellular cues direct axon-dendrite polarization in mouse developing neurons.

\section{Introduction}

In the developing neocortex, neocortical pyramidal neurons, which are primarily generated by radial glial cells (RGCs) in the ventricular zone (VZ; Miyata et al., 2001; Noctor et al., 2001; Götz and Huttner, 2005; Taverna et al., 2014) migrate through the

\footnotetext{
Received April 1, 2015; revised Sept. 1, 2015; accepted Sept. 13, 2015.

Author contributions: C.X. and K.K. designed research; C.X., Y.F., and T.N. performed research; C.X., T.W., T.T., and S.N. contributed unpublished reagents/analytic tools; C.X., Y.F., and T.W. analyzed data; C.X. and K.K. wrote the paper.

C.X. was supported by Monbukagakusho (MEXT) Scholars. This work was supported by MEXT KAKENHI Grants 25123705 and 22150003, and by the Japan Society for the Promotion of Science KAKENHI Grant 25251021 (A; to K.K.) A part of this study is the result of "Bioinformatics for Brain Sciences" performed under the Strategic Research Program of Brain Sciences by MEXT. We thank T. Kawauchi (Institute of Biomedical Research and Innovation), C. Gauthier-Rouviere (Centre de Recherche de Biochimie Macromoléculaire), Y. Tomooka (Tokyo University of Science), and A. Sakakibara (Chubu University) for plasmids and antibodies; F. Ishidate for help with image acquirement; D. Tsuboi, K. Kuroda, K. Matsuzawa, and M. Amano (Nagoya University) for helpful discussion and technical support; T. Ishii for secretarial assistance; and the Division for Medical Research Engineering of Nagoya University Graduate School of Medicine (I. Mizuguchi) for technical assistance.

The authors declare no competing financial interests.
}

subventricular zone (SVZ) and enter the intermediate zone (IZ) with multipolar morphology (Tabata and Nakajima, 2003; Bielas et al., 2004). These immature neurons subsequently transform from a multipolar morphology to a bipolar morphology, with a thick leading process and a thin trailing process, and migrate along radial glial fibers to the developing cortical plate $(\mathrm{CP}$; Tabata and Nakajima, 2003; LoTurco and Bai, 2006; Reiner and Sapir, 2009; Kawauchi et al., 2010; Govek et al., 2011; Nakamuta et al., 2011). The leading process becomes the dendrite, and the

Correspondence should be addressed to Dr. Kozo Kaibuchi, Department of Cell Pharmacology, Nagoya University Graduate School of Medicine, 65 Tsurumai, Showa, Nagoya 466-8550, Japan. E-mail: kaibuchi@med.nagoya-u.ac.jp.

T. Watanabe's present address: Department of Pharmacology, University of North Carolina at Chapel Hill School of Medicine, Chapel Hill, NC 27599.

T. Namba's present address: Max Planck Institute of Molecular Cell Biology and Genetics, Pfotenhauerstrasse 108, D-01307 Dresden, Germany.

DOI:10.1523/JNEUROSCI.1266-15.2015

Copyright $\odot 2015$ the authors $\quad 0270-6474 / 15 / 3514517-16 \$ 15.00 / 0$ 
trailing process becomes the axon (Noctor et al., 2001; Hatanaka and Murakami, 2002), indicating that radial glia-guided migration and axon-dendrite polarity may share similar polarized signaling pathways. However, how axon-dendrite polarization is directed by extracellular cues remains unclear.

Our previous study revealed that a transient axonal glycoprotein-1 (TAG-1)-dependent interaction between multipolar cells and preexisting axons enables these multipolar cells to specify the preexisting axon-contacting neurite as the axon and to develop into bipolar cells (Namba et al., 2014). These findings provide molecular and cellular mechanisms for the neuronal polarization of $\sim 60 \%$ of multipolar cells that extend trailing processes (nascent axons) before leading processes during their multipolar-to-bipolar transition (MBT; Namba et al., 2014). However, the remaining $40 \%$ of multipolar cells somehow specify their axon-dendrite polarity as well, likely through a complementary mechanism.

Cell-cell interactions play an essential role during the development of multicellular organisms. In particular, cell-cell contacts serve as a polarity cue that regulates intracellular organization and leads to the orientation of the cell polarity axis along which the cell grows, resulting in shape changes and movement (Halbleib and Nelson, 2006; Heuberger and Birchmeier, 2010; Etienne-Manneville, 2011). Thus, before and during RGCguided neuronal migration, N-cadherin-mediated RGC-pyramidal cell contact may also be necessary to establish neuronal polarity with a leading process and a trailing process (Fig. $1 A$ ). Furthermore, during our time-lapse imaging of individual multipolar cells undergoing the MBT in a cultured brain slice (Nakamuta et al., 2011), we observed that the leading-like process of the multipolar cell appeared to become stabilized by contacting something, after which the soma elongates to become spindle shaped and the axon gradually emerges from the opposite side of the contact side. Therefore, we speculated that the MBT and the subsequent radial glia-guided neuronal migration are highly coherent events and that both are directed by the N-cadherinmediated RGC-pyramidal cell interaction (Fig. 1A).

To examine our hypothesis, we here used an in vitro approach of coculturing RGCs with cortical neurons. As expected, we found that the N-cadherin-mediated RGC-cortical neuron interaction directs axon formation from the opposite side of the contact site. We also found that the $\mathrm{N}$-cadherin-mediated adhesions are required for the MBT of pyramidal cells in vivo.

\section{Materials and Methods}

Mice. Experiments using pregnant female mice were performed according to the guidelines of the Institute for Developmental Research and approved by The Animal Care and Use Committee of Nagoya University. Pregnant ICR female mice were obtained from Japan SLC.

siRNA, plasmids, and antibodies. The cDNA-encoding mouse $\mathrm{N}$-cadherin was provided by Cecile Gauthier-Rouviere (Centre de Recherche de Biochimie Macromoléculaire, Montpellier, France). The cDNA-encoding mouse E-cadherin was provided by Masayuki Ozawa (Kagoshima University, Kagoshima, Japan). pT $\alpha$-1-LPL (loxP-PolyAloxP) and pT $\alpha$-1-LPL-Lyn-enhanced green fluorescent protein (EGFP) were obtained as previously described (Nakamuta et al., 2011; Sakakibara et al., 2014). N-cadherin-W2A was generated by PCR-based site-directed mutagenesis (PrimeSTAR; Takara). The E/N chimera encoding the extracellular and transmembrane domains of E-cadherin (1-727 aa) and the cytoplasmic domain of $\mathrm{N}$-cadherin (747-906 aa) was generated using In-Fusion HD Cloning Kits (Clontech). The cDNAs encoding the $\mathrm{N}$-cadherin mutants were subcloned into the pEGFP-N1 (Clontech) vector. The cDNA encoding the $\mathrm{E} / \mathrm{N}$ chimera was subcloned into the pEGFP-N1 (Clontech) vector. The cDNA encoding C3T was subcloned into the pEGFP-C1 (Clontech) and pT $\alpha$-1-LPL vectors. The fragment cDNA encoding Rho-kinase-RB/PH (TT) was subcloned into the $\mathrm{pT} \alpha$ -
1-LPL vector. The cDNA encoding RhoA-N19 was subcloned into the pT $\alpha$-1-LPL vector. pCAGGS-Raichu-RhoA-CR was a gift from Michael Lin (Stanford University, CA) (plasmid \#40258, Addgene; Lam et al., 2012). pT $\alpha$-1-LPL-MCS1-dominant-negative N-cadherin (N-cad-DN) and pCAG-MCS2-N-cad-DN were provided by Takeshi Kawauchi (Institute of Biomedical Research and Innovation, Osaka, Japan). All constructs were confirmed by DNA sequencing. The target sequences for N-Cadherin RNAi $1^{\#}$ and RNAi $2^{\#}$ were as follows: $5^{\prime}$-CUGAGUUU CUGCACCAGGUTT-3', and 5'-GAGUUUACUGCCAUGACUUTT$3^{\prime}$, respectively. siRNA-resistant $\mathrm{N}$-cadherin was generated by mutating the targeted sequence of siN-cadherin $2^{\#}$ to the sequence $5^{\prime}$ GAATTTACCGCGATGACT-3' (the mutated nucleotides are shown in italics) using PCR-based site-directed mutagenesis. The following antibodies were used: monoclonal mouse anti-Myc (9E10; Santa Cruz Biotechnology); monoclonal mouse anti- $\alpha$-tubulin (DM1A; Sigma); monoclonal mouse anti-Tau-1 (Millipore); monoclonal mouse anticlass III $\beta$-tubulin and polyclonal rabbit anti-class III $\beta$-tubulin antibodies (Tuj-1; Covance); polyclonal rabbit anti-synapsin 1 (Calbiochem); monoclonal mouse anti- $\mathrm{N}$-cadherin (BD Transduction Laboratories); polyclonal rabbit anti-GFP and polyclonal rabbit anti-RFP antibodies (MBL); monoclonal rat anti-GFP antibody (Nacalai); polyclonal goat anti-TAG-1 antibody (R\&D Systems); and monoclonal mouse antiNestin (Cell Signaling Technology). The polyclonal rabbit anti-Nestin antibody was provided by Yasuhiro Tomooka (Tokyo University of Science, Tokyo, Japan). Alexa Fluor 488-, Alexa Fluor 555-, and Alexa Fluor 647-conjugated secondary antibodies against mouse or rabbit Ig or phalloidin were obtained from Invitrogen.

Coculture of cortical neurons with purified Nestin-positive cells. RGCs from embryonic day 15 (E15) mouse embryonic cerebral cortices were prepared as previously described (Gongidi et al., 2004; Kawauchi et al., 2010) with some modifications. E15 mouse embryonic cerebral cortices were dissected and dissociated into single cells in the same way as neuron dissociation (see below). Dissociated cells were suspended in Minimum Essential Medium (MEM) containing 10\% horse serum and plated into a six-well plate coated with $100 \mu \mathrm{g} / \mathrm{ml}$ poly-D-lysine (PDL; Sigma) at a density of $4.0 \times 10^{6}$ cells/well. After a 3 d culture, the cells from a six-well plate were passaged and plated into four six-well plates coated with 100 $\mu \mathrm{g} / \mathrm{ml}$ PDL. After another $3 \mathrm{~d}$ culture, Tuj-1-negative and Nestinpositive cells were concentrated. Purified Nestin-positive cells were then seeded on coverslips or glass-bottom dishes coated with $100 \mu \mathrm{g} / \mathrm{ml}$ PDL and cultured in MEM containing 10\% horse serum. Subsequently, primary cortical neurons from E15 embryonic cerebral cortices were prepared as previously described (Namba et al., 2014) and added at a density of $1.0 \times 10^{4}$ cells/well (24-well plate) or $0.8 \times 10^{5}$ cells/dish $(35 \mathrm{~mm}$ glass-bottom dish) to purified Nestin-positive cells. Following coculture in neurobasal medium (Invitrogen) supplemented with B-27 (Invitrogen) and $1 \mathrm{~mm}$ GlutaMAX (Invitrogen) for $2 \mathrm{~d}$, cells were processed for immunocytochemistry. Neurons were transfected following cell dissociation via nucleofection (Amaxa) and then cocultured with Nestinpositive cells. In siRNA transfection and rescue experiments, Nestinpositive cells or COS-7 cells were transfected using Lipofectamine 2000 reagent (Invitrogen) according to the manufacturer instructions. Immunoblot analysis was performed as previously described (Funahashi et al., 2013). For the Nestin-positive cell and cortical neuron interaction assay, $1 \mathrm{~d}$ following transfection dissociated cortical neurons were added to these transfected Nestin-positive cells and cocultured for $2 \mathrm{~d}$. In blocking experiments, Nestin-positive cells and cortical neurons were cocultured for $2 \mathrm{~h}$, followed by incubation with $6 \mu \mathrm{g} / \mathrm{ml} \mathrm{Fc}$-tagged $\mathrm{N}$-cadherin $\mathrm{N}$ terminus (N-cad-Fc; mouse; catalog \#6626-NC, R\&D Systems). After $2 \mathrm{~d}$ of incubation with $\mathrm{N}$-cad-Fc, cells were fixed and processed for immunocytochemistry. After $1.5 \mathrm{~h}$ of incubation with $\mathrm{N}$-cad-Fc, cells were analyzed using live cell imaging. In the screening assay for inhibitors, the phosphoinositide-3-kinase (PI3K) inhibitor LY294002 (Calbiochem), MEK inhibitor U0126 (Calbiochem), JNK inhibitor SP600125 (Calbiochem), or Src family kinase (SFK) inhibitor PP2 (Calbiochem) was added at the indicated concentration after $4 \mathrm{~h}$ of coculture of Nestin-positive cells and cortical neurons. After $44 \mathrm{~h}$ of incubation with the respective inhibitor, cells were fixed and processed for immunocytochemistry. 
A

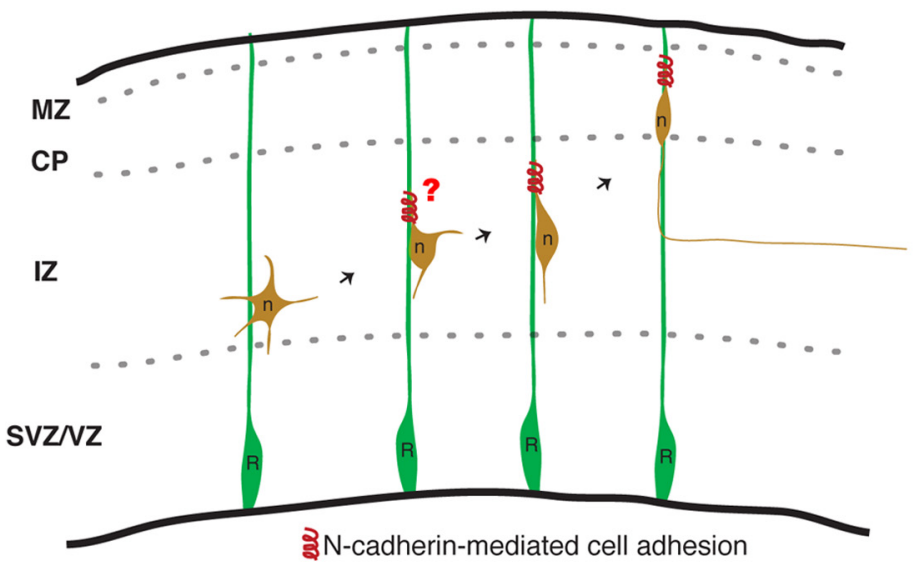

B
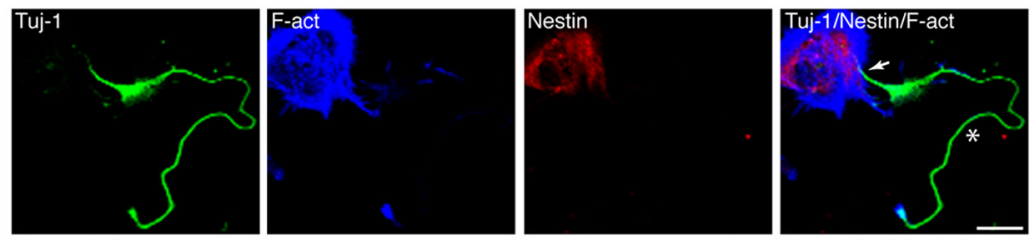

C
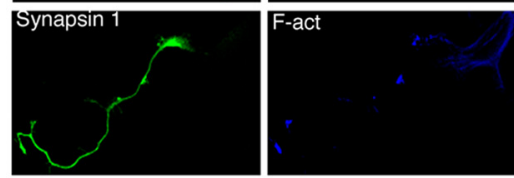

D
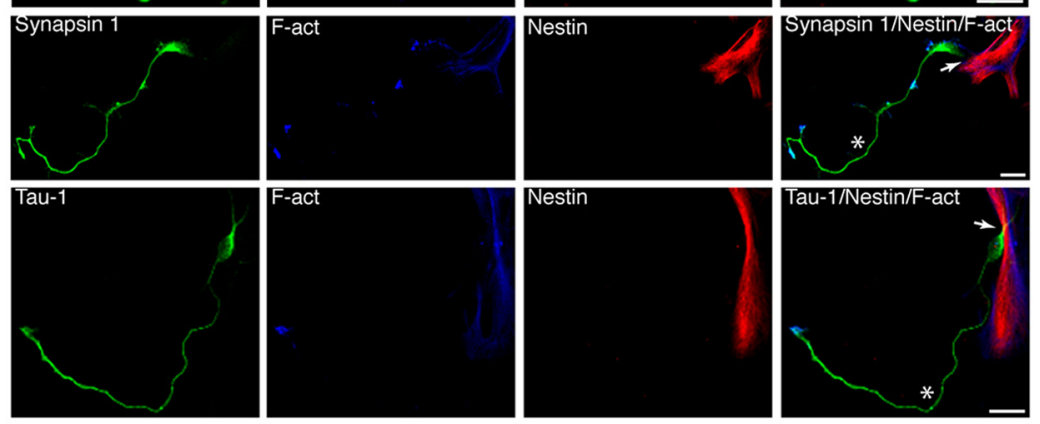

E

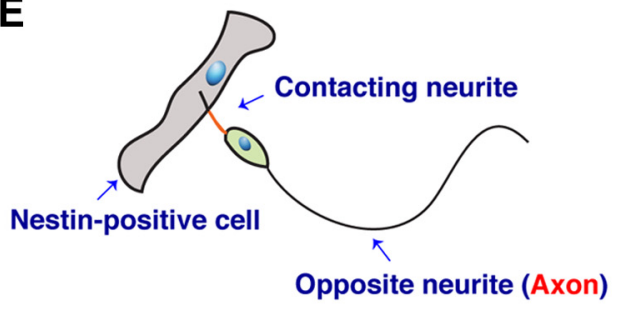

\section{- Length of contacting process}

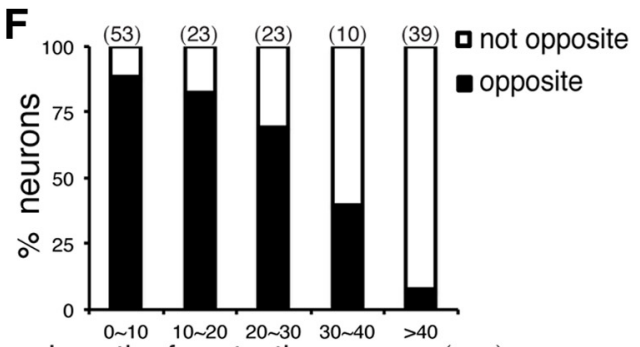

Length of contacting process $(\mu \mathrm{m})$

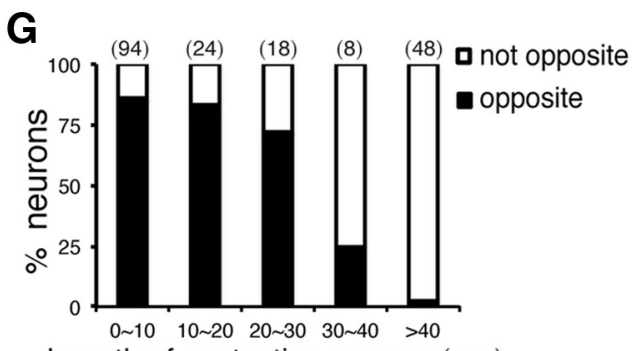

Length of contacting process $(\mu \mathrm{m})$

H

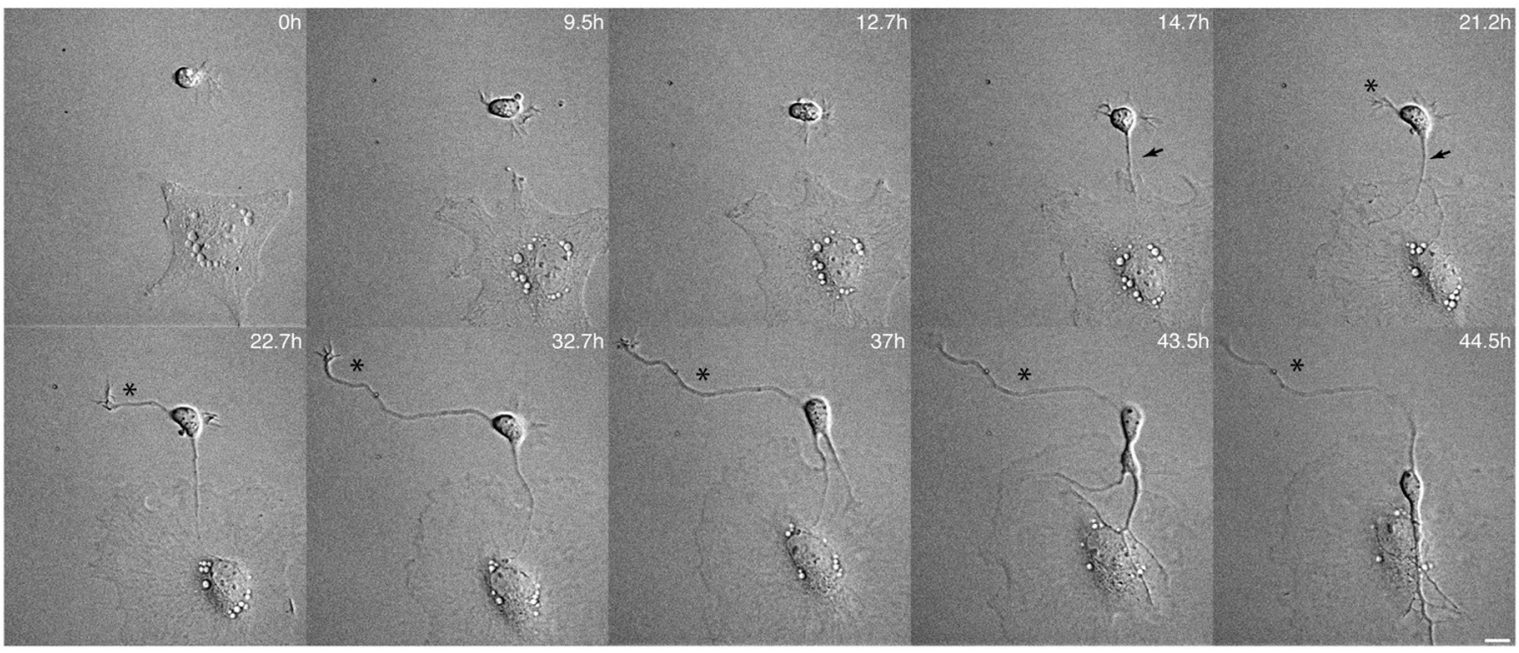

Figure 1. The Nestin-positive cell-cortical neuron interaction directs axon formation from the opposite side of the contacting neurite. $A$, Schematic diagram of the proposal that RGC-pyramidal cell interaction directs axon- dendrite polarization for the initiation of the subsequent Radial glia-guided neuronal migration. The leading-like process of a multipolar cell may already bind to a radial glial fiber through N-cadherin-mediated cell adhesion, and the binding itself may initiate the MBT. $\boldsymbol{B}-\boldsymbol{D}$, Representative images of the interaction between Nestin-positive cells (red) and cortical neurons (green) in vitro. Axons form from the side of the cortical neuron opposite the Nestin-positive cell-contacting neurite. Arrows and asterisks indicate the Nestin-positive cell-contacting neurite and nascent axon, respectively. Nestin-positive cells and cortical neurons were cocultured for $2 \mathrm{~d}$, and cells were subsequently immunostained with the indicated antibodies. Tuj-1, neuron marker; Tau-1 and Synapsin-1, axon marker; Nestin, radial glial cell marker; and F-act, stained with Alexa Fluor 647-conjugated phalloidin (blue). Scale bars, $20 \mu \mathrm{m}$. E, Schematic diagram of a typical Nestin-positive cell-cortical neuron interaction. Along the somatic polarity axis, the axon forms on the side opposite the Nestin-positive cell-contacting neurite. $F, G$, Quantitative analysis of the direction of axon formation. The length of the contacting process is indicated in $\boldsymbol{E}$. The number above each bar indicates the total number of examined Nestin-positive cell-contacting neurons. $\boldsymbol{F}$, Neurons were labeled with the neuronal marker Tuj-1, and Nestin-positive cells were labeled with F-actin and the radial glia marker Nestin. $\mathbf{G}$, Neurons were labeled with the neuron marker Tuj-1 and the axonal marker Tau-1. Nestin-positive cells were labeled with F-act. $\boldsymbol{H}$, Time-lapse images of the interaction between cocultured Nestin-positive cells and cortical neurons. Images were acquired every $10 \mathrm{~min}$. Arrows and asterisks indicate the Nestin-positive cell-contacting neurite and the axon, respectively. Scale bars, $10 \mu \mathrm{m}$. F-act, F-Actin; MZ, marginal zone; R, radial glial cell; n, pyramidal neuron. 
Coculture of cortical neurons with L cells. L cells were seeded on coverslips coated with 100 $\mu \mathrm{g} / \mathrm{ml} \mathrm{PDL}$ and cultured in DMEM containing $10 \%$ fetal bovine serum. L cells were transfected using Lipofectamine 2000 reagent according to the manufacturer instructions. One day following transfection, dissociated cortical neurons were added at a density of $1.0 \times 10^{4}$ cells/well (24-well plate) to these transfected L cells. Following coculture in neurobasal medium supplemented with B-27 and $1 \mathrm{~mm}$ GlutaMAX for $2 \mathrm{~d}$, cells were processed for immunocytochemistry.

Lattice culture. Dorsal neocortices were dissected, and cortical cultures were prepared from E15 mouse embryos with papain as previously described (Nichols et al., 2008) with some modifications. Cells were plated in neurobasal medium (Invitrogen) supplemented with B-27 (Invitrogen) and $1 \mathrm{~mm}$ GlutaMAX (Invitrogen) on $35 \mathrm{~mm}$ glass-bottom dishes coated with $25 \mu \mathrm{g} / \mathrm{ml}$ PDL $\left(2.5 \times 10^{6}\right.$ cells/ dish). Cultures were maintained in a $37^{\circ} \mathrm{C}, 5 \%$ $\mathrm{CO}_{2}$ incubator. After $1 \mathrm{~d}$ in vitro, lattice cultures were induced with $100 \mu \mathrm{g} / \mathrm{ml} 5 \mathrm{kDa}$ dextran sulfate (MP Biomedicals). After $3 \mathrm{~h}$, movies were acquired using an incubator microscope system (LCV110, Olympus) with a 15 min time interval between frames. The images were processed using MetaMorph software (Molecular Devices).

Immunocytochemistry and live cell imaging. For immunocytochemistry, cells were fixed with $3.7 \%$ formaldehyde in PBS for $10 \mathrm{~min}$ at room temperature, followed by treatment with $0.05 \%$ Triton X-100 for 10 min on ice. After blocking with $10 \%$ goat serum albumin in PBS, cells were incubated with each indicated antibody overnight at $4^{\circ} \mathrm{C}$. After three washes with PBS, the samples were incubated with the appropriate secondary antibodies. The following analysis was performed using an LSM 780 or LSM5 confocal laser-scanning microscope under the control of LSM software (Carl Zeiss). For live cell imaging, Nestin-positive cells and cortical neurons were cocultured for $2 \mathrm{~h}$ and analyzed using an incubator microscope system (LCV110, Olympus). The images were processed using MetaMorph software (Molecular Devices).

In utero electroporation. In utero electroporation was performed as previously described (Nakamuta et al., 2011) with some modifications. pT $\alpha$-1-LPL-Lyn-EGFP $(0.3 \mu \mathrm{g} / \mu \mathrm{l})$ was comicroinjected with pT $\alpha$-1-Cre $(0.01 \mu \mathrm{g} / \mu \mathrm{l})$ and pT $\alpha-1-\mathrm{MCS} 1-\mathrm{N}-\mathrm{cad}-\mathrm{DN}, \mathrm{pT} \alpha-1-\mathrm{LPL}-$ Rho-kinase-DN, pT $\alpha$-1-LPL-RhoA-DN, pT $\alpha$ 1-LPL-C3T, or pCAG-myc-Rho-kinase-DN (1 $\mu \mathrm{g} / \mu \mathrm{l})$. Following microinjection of the plasmids into the lateral ventricle of the embryos of either sex, electric pulses (50 ms square pulses of $27.5 \mathrm{~V}$ with $950 \mathrm{~ms}$ intervals) were applied to the embryos of either sex.

Immunohistochemistry and quantitative analysis. The brains were fixed in 4\% paraformaldehyde at E15 or E16.5 and coronally sectioned using a cryostat (Leica Microsystems) at a thickness of $60 \mu \mathrm{m}$. The slices were incubated with primary antibodies diluted in PBS containing 1\% BSA and $0.01 \%$ Triton X-100 at $4^{\circ} \mathrm{C}$ overnight. After three washes with PBS, the slices were treated with Alexa Fluor 488- or Alexa Fluor 555-conjugated secondary antibodies diluted in PBS containing 1\% BSA and 0.01\% Triton X-100 for $1 \mathrm{~h}$ at room temperature. The nuclei were visualized by staining with Hoechst 33342 (Invitrogen). Confocal images were recorded using LSM 780 or LSM5
Pascal microscopes built around an Axio Observer Z1 or Axiovert 200M with Plan-Apochromat 20× [numerical aperture (NA) 0.75], PlanApochromat $20 \times$ (NA 0.8), C-Apochromat 40× (NA 1.2), or Plan Apochromat $63 \times(\mathrm{NA} 1.40)$ lenses under the control of LSM software (Carl Zeiss) or a Nikon Al confocal laser-scanning microscope built around an ECLIPSE Ti with CFI Plan Apo VC $20 \times$ (NA 0.75) or CFI Plan Apo VC 60× WI (NA 1.2) lenses under the control of NIS-Elements software (Nikon). The distribution and morphology of migrating neurons were analyzed as previously described (Funahashi et al., 2013). The coronal sections of cerebral cortices containing the labeled cells were classified into two regions, CP and IZ, as previously described (Kawauchi et al., 2003). The number of labeled cells in each region was calculated. To evaluate the morphology of the migrating neurons, projection images of EGFPpositive neurons were obtained from Z-series confocal images using LSM 

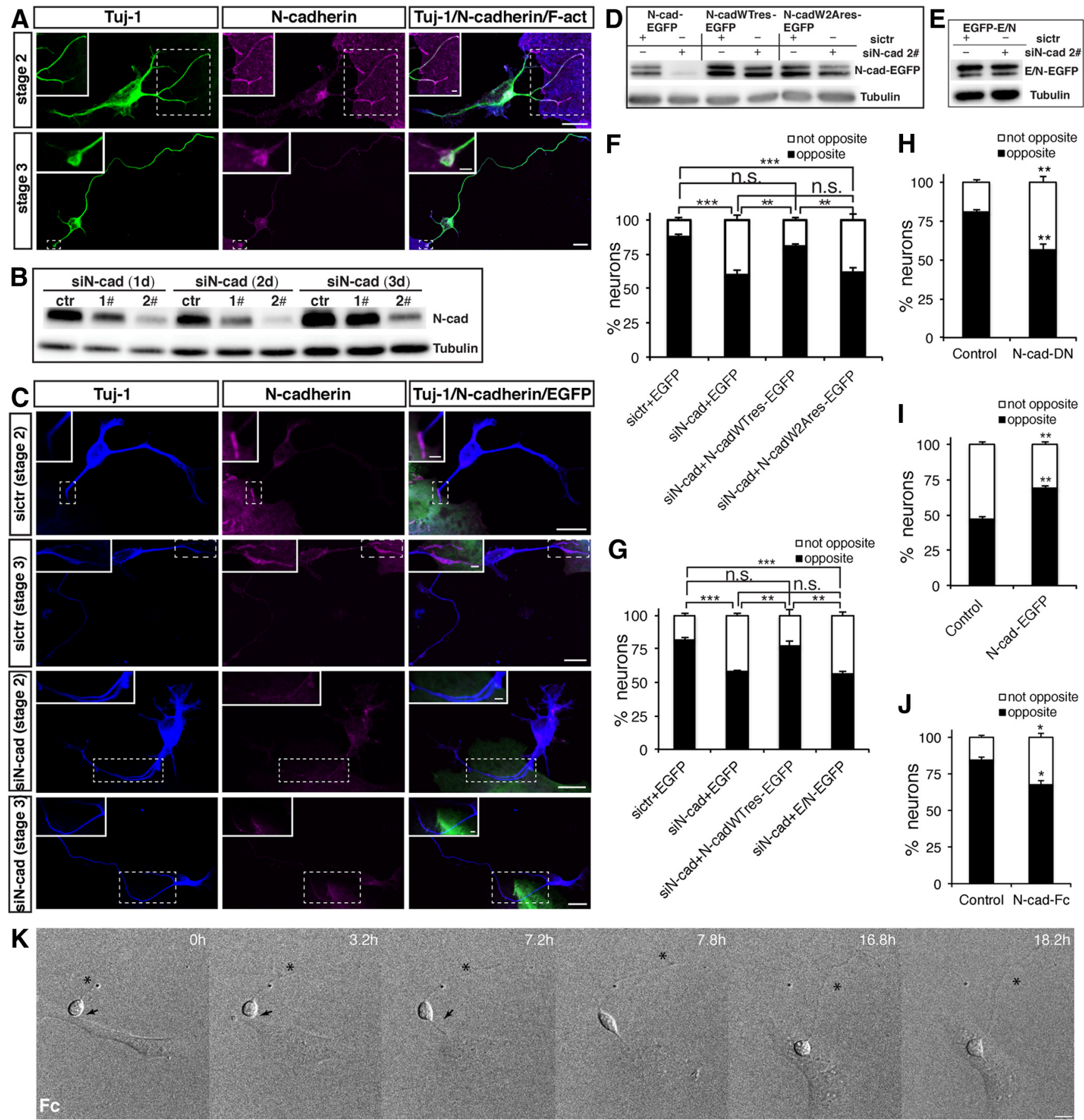

$\mathbf{L}$

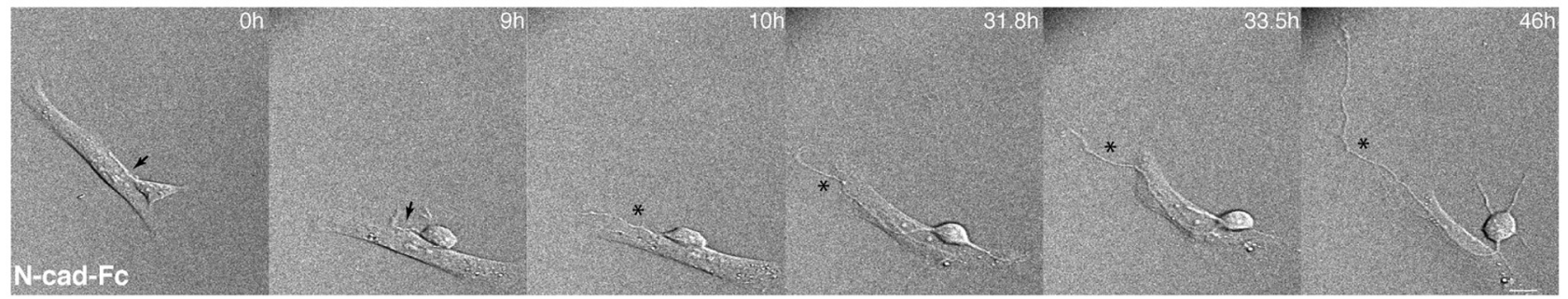

Figure 2. N-cadherin is required for the Nestin-positive cell-cortical neuron interaction in vitro. $A, C$, The distribution of $\mathrm{N}$-cadherin at the contact sites between neurons and Nestin-positive cells under various experimental conditions. $A$, Nestin-positive cells and cortical neurons were cocultured for $1 \mathrm{~d}$, and the cells were subsequently immunostained with the indicated antibodies. $C$, Purified Nestin-positive cells were transfected with control siRNA or siN-cad 2 $2^{\#}$ plus pEGFP. The following day, the transfected Nestin-positive cells were cocultured with dissociated cortical neurons for $1 \mathrm{~d}$, and the cells were subsequently immunostained with the indicated antibodies. Scale bars, $10 \mu \mathrm{m}$. Magnification of the boxed region shows the distribution of $\mathrm{N}$-cadherin at the contact site between the Nestin-positive cell and cortical neuron. Scale bars, $2 \mu \mathrm{m}$. B, Lysates from purified Nestin-positive cells transfected with the indicated siRNA were subjected to immunoblot analysis using the indicated antibodies. $\boldsymbol{D}, \boldsymbol{E}$, Lysates from COS-7 cells transfected with the indicated siRNA and plasmids were subjected to immunoblot analysis using the indicated antibodies. $\boldsymbol{F}, \mathbf{G}$, Quantitative analysis of the direction of axon formation. Purified Nestin-positive cells transfected with the indicated siRNA and plasmid were cocultured with dissociated (Figure legend continues.) 
software. At least three independent fetal brains were electroporated and analyzed for each experiment.

Fluorescence resonance energy transfer. Cells transfected with the fluorescence resonance energy transfer (FRET) probe Raichu-RhoA-ClovermRuby2 (Raichu-RhoA-CR) were imaged using a cooled EMCCD camera (iXon DU-897, Nikon) and an UplanApo 40× (NA 0.9) oilimmersion objective (Olympus) on an IX-81 inverted fluorescence microscope (Olympus) controlled by MetaMorph software (Molecular Devices). FRET and donor emission images were acquired using the following filters: excitation (ex) 485/30 nm and emission (em) 530/40 $\mathrm{nm}$ for Clover, and ex 485/30 nm and em 595/70 nm for Clover-mRuby 2 FRET. The ratio of mRuby2 to Clover, as determined by the MetaFluor software, represents the FRET signal, which is proportional to the RhoA activity.

Statistics. The data are expressed as the mean \pm SEM. Statistical analyses were performed using GraphPad Prism versions 4.01 and 6 for Student's $t$ test and Tukey's multiple-comparison test. A $p$ value $<0.05\left(^{*}\right)$ was considered to indicate statistical significance.

\section{Results}

Nestin-positive cell-cortical neuron interactions direct axon formation at the opposite side of the cell from the contacting neurite

To evaluate whether interactions between radial glial cell and multipolar cells initiate axon-dendrite polarization, we performed in vitro neuron-radial glia interaction assay (Gongidi et al., 2004). The purified RGCs were strongly F-actin positive with fibroblast-like or elongated morphology and expressed the radial glial marker Nestin (Fig. $1 B-D$ ). Therefore, we call these purified RGCs "Nestin-positive cells." Primary cortical neurons dissociated from E15 mouse cerebral cortices were added to these purified Nestin-positive cells and cocultured for $2 \mathrm{~d}$. As predicted by our hypothesis, in cortical neuron, which were identified as Tuj1-positive cells, the axon formed from the opposite side of the soma from the Nestin-positive cell-contacting neurite (along the long axis of the soma; Fig. $1 B$ ). We defined axon formation from the opposite $90^{\circ}$ of arc from the contacting neurite as opposite, and axon formation from the $90^{\circ}$ of arc from the contacting neurite as not opposite. We then measured the length of the contacting process, as indicated in the schematic diagram in Figure $1 E$. In most cases, the length of the contacting process was $<20 \mu \mathrm{m}$. When the length of the contacting process was $<20$

$\leftarrow$

(Figure legend continued.) cortical neurons for $2 \mathrm{~d}$, and the cells were subsequently analyzed by immunostaining. Neurons were labeled with Tuj-1, and Nestin-positive cells were labeled with GFP and Nestin. ${ }^{* *} p<0.01,{ }^{* *} p<0.001$, Tukey's multiple-comparison test. n.s., Not significant. Error bars represent the SEM. $n \geq 40$ Nestin-positive cell-interacting neurons. $\boldsymbol{H}$, Quantitative analysis of the direction of axon formation. Cortical neurons transfected with pCAG-myc-GST or cotransfected with pCAG-myc-GST and pCAG-MCS2-N-cadherin-DN were cocultured with purified Nestin-positive cells for $2 \mathrm{~d}$, and the cells were subsequently analyzed by immunostaining. Neurons were labeled with Myc, and Nestin-positive cells were labeled with F-act and N-cadherin. ${ }^{* *} p<0.01$, Student's $t$ test. Error bars represent the SEM. $n \geq 40$ Nestin-positive cell-interacting neurons. $I$, Quantitative analysis of the direction of axon formation. $L$ cells transfected with the indicated plasmid were cocultured with dissociated cortical neurons for $2 \mathrm{~d}$, and the cells were subsequently analyzed by immunostaining. Neurons were labeled with Tuj- 1 and Hoechst, and L cells were labeled with GFP and Hoechst. ${ }^{* *} p<0.01$, Student's $s$ test. Error bars represent the SEM. $n \geq 40 \mathrm{~L}$ cell-interacting neurons. J, Quantitative analysis of the direction of axon formation. Nestin-positive cells and cortical neurons were cocultured in the presence of the $\mathrm{Fc}$ control or $\mathrm{N}-$ cad-Fc for $2 \mathrm{~d}$, and the cells were subsequently analyzed by immunostaining. Neurons were labeled with Tuj-1, and Nestin-positive cells were labeled with F-actin and Nestin. ${ }^{*} p<0.05$, Student's $t$ test. Error bars represent the SEM. $n \geq$ 40 Nestin-positive cell-interacting neurons. $\boldsymbol{K}, \boldsymbol{L}$, Time-lapse images of the interaction between Nestin-positive cells and cortical neurons under various experimental conditions. Arrows and asterisks indicate the Nestin-positive cell-contacting neurite and the nascent axon, respectively. Scale bars, $10 \mu \mathrm{m}$. $\mu \mathrm{m}, \sim 86.8 \%$ of the cortical neurons formed axons on the side of the soma opposite of the Nestin-positive cell-contacting neurite (Fig. $1 F$ ). When the length of the contacting process was $>40$ $\mu \mathrm{m}$, in $92.3 \%$ of the cortical neurons, the contacting process is axon (Fig. $1 F$ ), indicating that a Nestin-positive cell-cortical neuron interaction did not reverse the identity of an existing axon. During the following experiments, we analyzed only the interactions between Nestin-positive cells and cortical neurons with contacting processes of $<20 \mu \mathrm{m}$. We also confirmed these findings by immunostaining with antibodies against the axonal markers Tau-1 and Synapsin-1 (Fig. 1C,D, G). Collectively, our findings suggest that axons of cortical neurons form at the opposite side of the soma from the contacting neurite during a Nestinpositive cell-cortical neuron interaction in vitro.

Next, we directly determined whether a causal relationship exists between the Nestin-positive cell-cortical neuron interaction and axon formation opposite of the contacting neurite by performing time-lapse imaging experiments. Two hours after the coculture of Nestin-positive cells and cortical neurons, we began monitoring Nestin-positive cell-cortical neuron interactions. We observed that stage 1 cortical neurons with lamellipodial and filopodial protrusions gradually begin to dynamically extend and retract neurites, similar to multipolar cells in vivo. Once a neurite is attracted by and contacts a Nestin-positive cell, the soma elongates and an axon initiates and elongates from the opposite side of the cortical neuron, as occurs in bipolar cells in vivo, and the newly polarized cortical neuron migrates along the Nestinpositive cell (Fig. $1 \mathrm{H}$, Movie 1). This behavior resembles MBT and the subsequent neuronal locomotion along radial glia, both of which are highly coherent events directed by the Nestin-positive cell-cortical neuron interaction in this timelapse imaging. Moreover, using time-lapse imaging, this behavior was also observed during the formation of lattice cultures. Similarly, once the cortical neuron contacts the radial glial fiber, the cortical neuron undergoes MBT with axon formation from the opposite side of the radial glia-contacting neurite and migrates along the radial glial fiber (Movie 2). This finding indicates that cultured RGCs without glial fibers are sufficient to direct neuronal polarization, whereas neuronal migration along cultured radial glia requires glial fibers. Collectively, these observations demonstrate that in vitro a Nestin-positive cell-cortical neuron interaction directs axon formation at the opposite side of the soma from the contacting neurite.

\section{$\mathrm{N}$-cadherin mediates the functional interaction between Nestin-positive cells and cortical neurons}

In migrating neurons, $\mathrm{N}$-cadherin is required to establish dynamic adhesions with RGCs during glia-dependent migration (Kawauchi et al., 2010). We therefore reasoned that $\mathrm{N}$-cadherin also mediates the functional interaction between RGCs and unpolarized cortical neurons that directs axon formation. Indeed, $\mathrm{N}$-cadherin accumulated at the contact site between the Nestin-positive cell and stage 2 or stage 3 cortical neuron (Fig. 2A). We then assayed two different small interfering RNA ( $\operatorname{siN}$-cad $1^{\#}$ and $2^{\#}$ ) to knock down N-cadherin expression in purified Nestin-positive cells and determined that siN-cad $2^{\#}$ was more effective (Fig. $2 B$ ). Coexpression of siN-cad $2^{\#}$ with EGFP allowed the detection of transfected cells and effectively disrupted the recruitment of $\mathrm{N}$-cadherin in the cortical neuron to the contact site between the Nestinpositive cell and stage 2 or stage 3 cortical neuron (Fig. 2C). Interestingly, the physical cell-cell contact remained (Fig. 


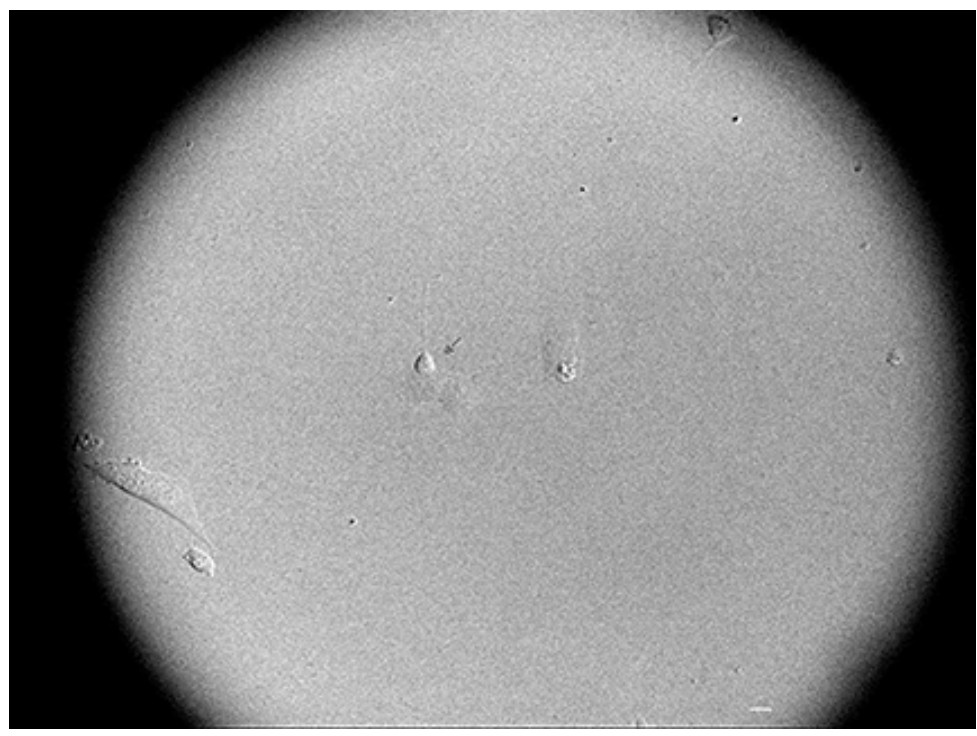

Movie 3. Time-lapse imaging analysis of the Nestin-positive cell-cortical neuron interaction in vitro. Nestin-positive cells and cortical neurons were cocultured in the presence of the Fc control. Images were acquired every $10 \mathrm{~min}$ ( $93.3 \%$ of Nestin-positive cell-interacting neurons exhibited axon formation at the opposite side of the soma from the contacting neurite, $n=15$ Nestinpositive cell-interacting neurons in 11 movies). Scale bar, $10 \mu \mathrm{m}$. Arrow indicates Nestin-positive cell-contacting cortical neuron.

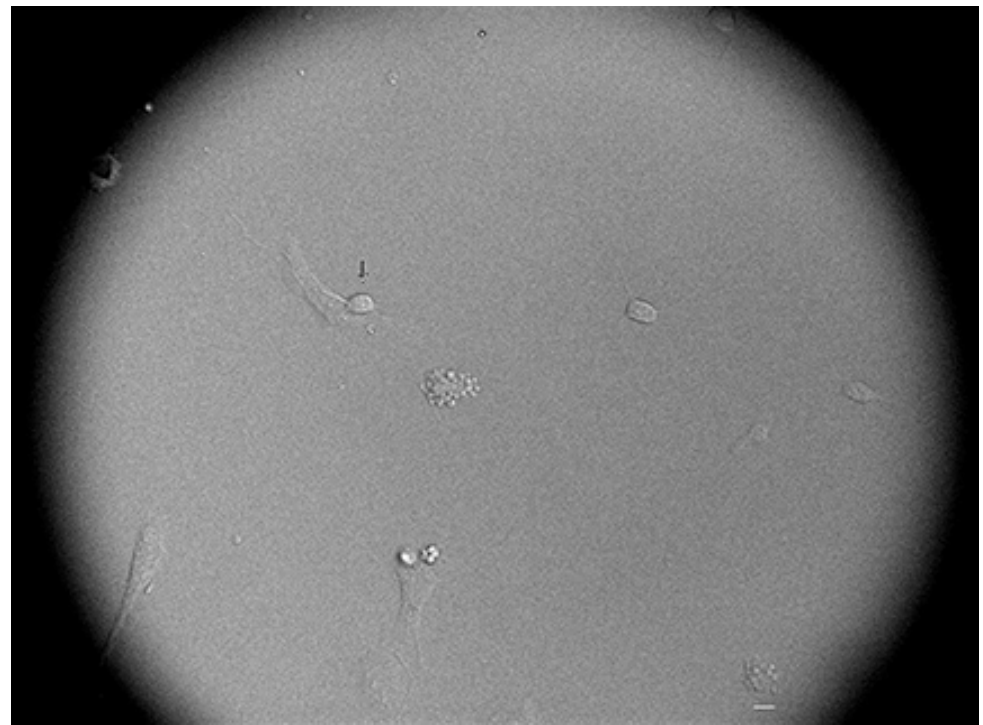

Movie 4. Time-lapse imaging analysis of the Nestin-positive cell-cortical neuron interaction in vitro. Nestin-positive cells and cortical neurons were cocultured in the presence of N-cad-Fc. Images were acquired every $10 \mathrm{~min}$ ( $25 \%$ of Nestin-positive cellinteracting neurons exhibited axon formation at the opposite side of the soma from the contacting neurite, $n=20$ Nestin-positive cell-interacting neurons in 17 movies). Scale bar, $10 \mu \mathrm{m}$. Arrow indicates Nestin-positive cell-contacting cortical neuron.

2C). The physical cell-cell contact may have been maintained by other receptors, such as Junctional adhesion molecules or nectins, despite impaired N-cadherin function. Notably, following $\mathrm{N}$-cadherin knockdown, the interaction of the cortical neuron with the Nestin-positive cell failed to direct axon formation at the side of the soma opposite the contacting neurite (Fig. 2C,F). Because $\mathrm{N}$-cadherin was no longer recruited to the contact site (Fig. 2C), this finding indicates that $\mathrm{N}$-cadherinmediated adhesion is important to direct axon formation to the opposite side.

To further confirm that $\mathrm{N}$-cadherin-mediated adhesion between Nestin-positive cells and cortical neurons directs the site of axon formation, we evaluated the extent to which a mutated form of
$\mathrm{N}$-cadherin (N-cadW2A), which abrogates its adhesive capacity and fails to form $\mathrm{N}$-cadherin-N-cadherin interaction (Tamura et al., 1998; Tabdili et al., 2012), or the $\mathrm{E} / \mathrm{N}$ chimera, which encodes the extracellular and transmembrane domains of E-cadherin and the cytoplasmic domain of $\mathrm{N}$-cadherin, could rescue the phenotype caused by knockdown of N-cadherin. For this purpose, we used an siRNA-resistant form of wild-type (WT) N-cadherin (NcadWTres) and an siRNA-resistant form of $\mathrm{N}$-cadW2A (N-cadW2Ares). The coexpression of siN-cad $2^{\#}$ and N-cadWTres, $\mathrm{N}$-cadW2Ares, or E/ $\mathrm{N}$ restored the expression of N-cadherin (WT, W2A, or E/N; Fig. $2 D, E)$. As expected, WT N-cadherin rescued the phenotype caused by $\mathrm{N}$-cadherin knockdown, whereas $\mathrm{N}$-cadW2A or $\mathrm{E} / \mathrm{N}$ was unable to rescue it (Fig. $2 F, G$ ). To inhibit $\mathrm{N}$-cadherin function in cortical neurons, we used a N-cad-DN $(\Delta 390)$ expressing construct, as previously described (Kawauchi et al., 2010), which can inhibit the function of endogenous $\mathrm{N}$-cadherin. The inhibition of endogenous $\mathrm{N}$-cadherin function in cortical neurons by expression of $\mathrm{N}$-cad-DN affected axon formation at the opposite side of the cell (Fig. 2H). To evaluate whether $\mathrm{N}$-cadherin-mediated adhesion is sufficient to direct axon formation at the opposite side of the cell, we expressed $\mathrm{N}$-cadherin in $\mathrm{L}$ cells, which do not express endogenous $\mathrm{N}$-cadherin, and cocultured these $\mathrm{L}$ cells with cortical neurons. We found that the expression of $\mathrm{N}$-cadherin in L cells notably increased the number of cortical neurons with axon formation at the side of the soma opposite of the L cell-contacting neurite (Fig. 2I).

To verify that the inhibition of $\mathrm{N}$-cadherin-mediated adhesion between Nestin-positive cells and cortical neurons affects oriented axon formation, we cocultured Nestin-positive cells with cortical neurons in the presence of either $\mathrm{Fc}$ alone, as the control, or the N-cad-Fc (residues 1-724) and then analyzed the oriented axon formation. In the presence of the control Fc fragments, the cocultured Nestin-positive cells and cortical neurons exhibited a clear bias of axon formation from the opposite side of the cortical neuron from the contacting neurite (Fig. $2 J$ ). In contrast, we found that the inhibition of $\mathrm{N}$-cadherin-mediated adhesion with soluble $\mathrm{N}$-cad-Fc affects the oriented axon formation. We also performed time-lapse analysis of axon initiation and elongation in Nestin-positive cell-contacting cortical neurons in the presence of the Fc control or N-cad-Fc. Compared with the controls, the Nestinpositive cell-cortical neuron interaction no longer directed axon formation to the side of the cortical neuron opposite of the contacting neurite (Fig. 2 K, L, Movies 3, 4). Collectively, these results demonstrate that an $\mathrm{N}$-cadherin-mediated 
A Hoechst N-cad $\square$ TAG-1

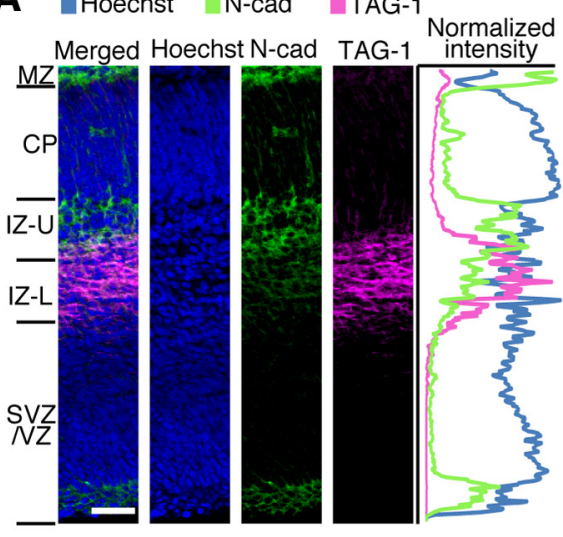

C

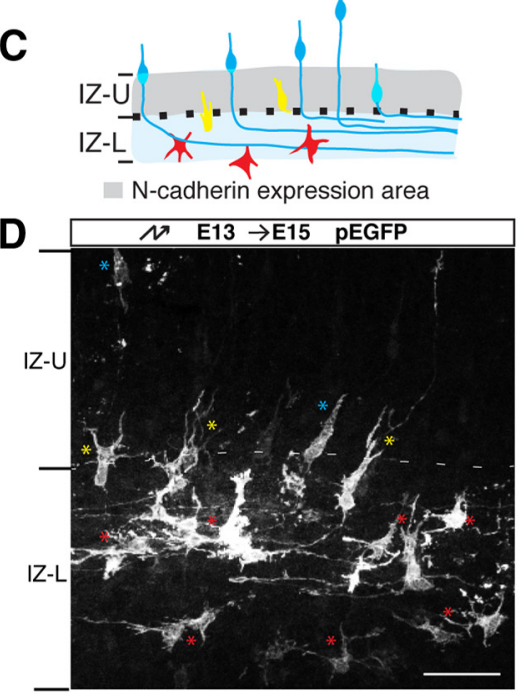

B

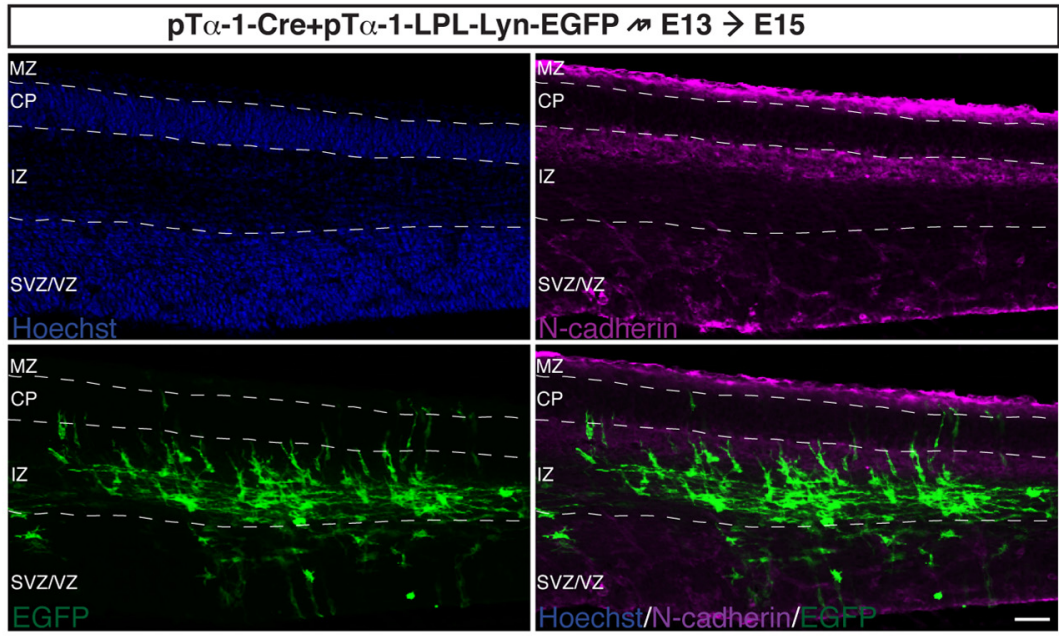

E

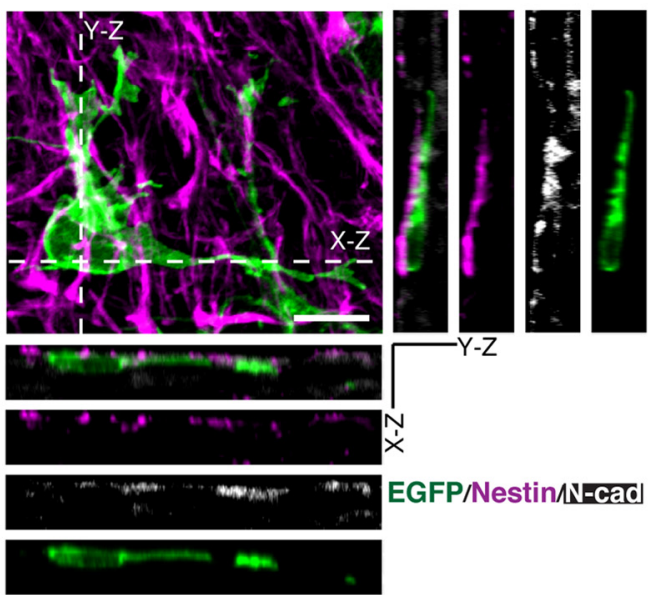

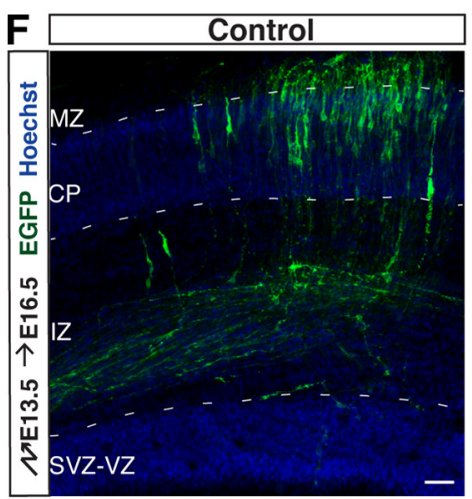

G

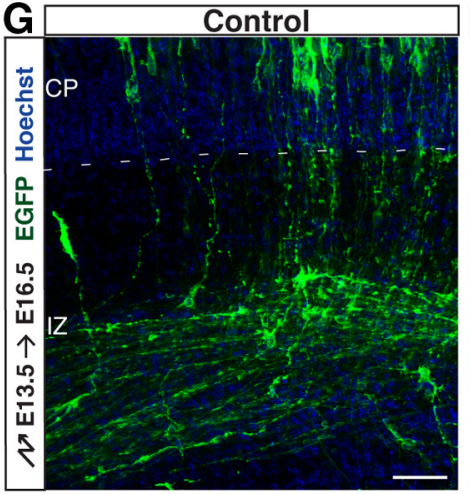

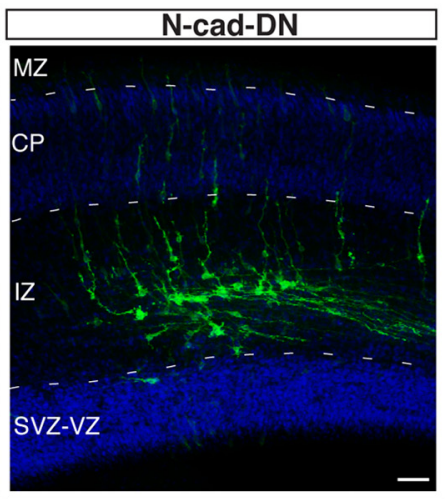

N-cad-DN

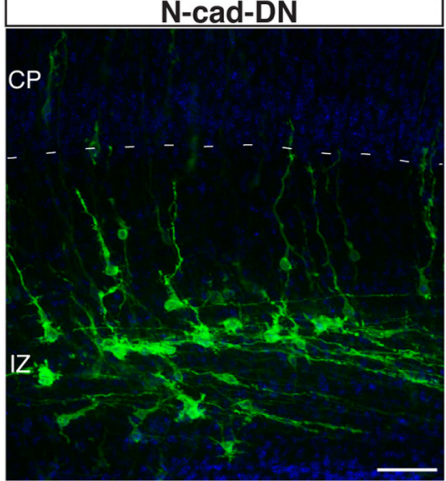

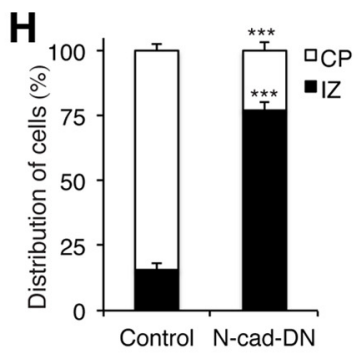

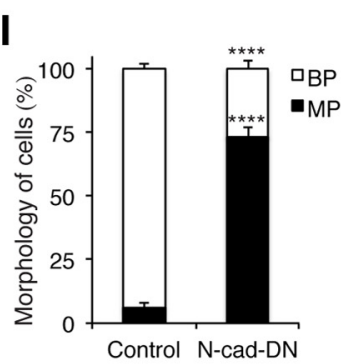


Nestin-positive cell-cortical neuron interaction directs axon formation opposite of the contacting neurite.

\section{$\mathrm{N}$-cadherin-dependent RGC-pyramidal cell interaction mediates $\mathrm{MBT}$ in vivo}

To extend these findings in vivo and to determine whether an $\mathrm{N}$-cadherin-mediated RGC-pyramidal cell interaction is required for MBT, we first used immunohistochemistry to analyze the pattern of $\mathrm{N}$-cadherin expression and its relationship to the localization of bipolar cells in the developing neocortex. For this purpose, we cotransfected $\mathrm{pT} \alpha$-1-Cre and $\mathrm{pT} \alpha$-1-LPL-LynEGFP into progenitor cells at E13 using in utero electroporation and killed the embryos at E15 for immunohistochemistry, as previously described (Nakamuta et al., 2011). At E15, N-cadherin was prominently expressed in the MZ, the upper IZ, and the luminal surface of the ventricle (Fig. $3 A, B$ ). The lower IZ was indicated by the expression of the efferent axon marker TAG-1 (Fig. 3A). Most cells that expressed membrane-targeted EGFP (Lyn-EGFP) under the control of the neuron-specific T $\alpha$-1 promoter had already migrated into the IZ. Moreover, and consistent with the findings of previous studies (Noctor et al., 2004; Jossin and Cooper, 2011; Namba et al., 2014), most cells in the upper IZ exhibited bipolar morphology, whereas most cells in the lower IZ exhibited multipolar morphology (Fig. 3B-D). In addition, the appearance of bipolar cells notably coincided with the appearance of predominant $\mathrm{N}$-cadherin expression in the upper IZ (Fig. $3 B, C$ ). In the boundary region between the lower IZ and upper IZ, there were cells with morphologies that were distinct from bipolar or multipolar morphologies. Typically, these cells possessed two leading processes or one leading process with branches, which were defined as leading-like processes, toward the $\mathrm{CP}$ and zero or one trailing process (Fig. $3 C, D$ ). Indeed, the leading-like process of the neuron expressing Lyn-EGFP under the control of the $\mathrm{T} \alpha-1$ promoter was bound to and guided along Nestin-positive radial glial fiber (Fig. 3E). Moreover, $\mathrm{N}$-cadherin accumulated at the contact site between the leadinglike process and the radial glial fiber (Fig. 3E), which is consistent with the notion that the N-cadherin-mediated RGC-pyramidal cell interaction may engage in the MBT.

To further confirm that an N-cadherin-mediated RGC-pyramidal cell interaction is required for the MBT, we evaluated neuronal morphology following the inhibition of N-cadherin in pyramidal

$\leftarrow$

Figure 3. The N-cadherin-mediated RGC-cell interaction is required for MBT. $A$, Sections of E15 mouse neocortex labeled with the corticofugal axon marker TAG-1, N-cadherin, and the Hoechst nuclear stain to indicate the expression pattern of $\mathrm{N}$-cadherin in the mouse neocortex. Scale bar, $50 \mu \mathrm{m} . \boldsymbol{B}, \boldsymbol{D}$, Representative images showing the positions of electroporated neurons and the expression pattern of $\mathrm{N}$-cadherin. The mice were electroporated at E13 and fixed at E15. GFP (green), N-cadherin (magenta), and Hoechst (blue) staining are shown in $\boldsymbol{B}$. In $\boldsymbol{D}$, red asterisks indicate multipolar cells; yellow asterisks indicate cells with leading-like processes; blue asterisks indicate bipolar cells; and dashed lines indicate the boundary region between the lower and upper IZ. Scale bar, $50 \mu \mathrm{m}$. C, Model of the N-cadherin expression pattern and the morphology of pyramidal cells in the IZ. $\boldsymbol{E}$, Representative images of the N-cadherin-mediated interaction between the leading-like process of an unpolarized GFP-labeled pyramidal cell (green) and a Nestin-positive radial glial fiber (magenta) in E15 mouse neocortex. The bottom and right panels represent the $x$ - to $z$-axis and $y$ - to $z$-axis images, respectively. $N$-cadherin (white) staining is shown. Scale bar, $10 \mu \mathrm{m} . \boldsymbol{F}, \boldsymbol{G}$, Sections of E16.5 mouse neocortex electroporated with the indicated plasmids plus pT $\alpha$-1-LPL-Lyn-EGFP at E13.5. $\boldsymbol{H}$, Quantification of the distribution of electroporated cells from $\boldsymbol{F}$ in distinct regions of the neocortex (CP and IZ). ${ }^{* * *} p<0.001$, Student's $t$ test. Error bars represent the SEM. I, The percentage of electroporated cells from $\boldsymbol{G}$ with bipolar (BP) or multipolar (MP) morphologies in the neocortex. ${ }^{* * *} p<$ 0.0001 , Student'st test. Error bars represent the SEM. IZ-L, Lower IZ; IZ-U, upper IZ. Scale bar, $50 \mu \mathrm{m}$. cells using a dominant-negative approach. The expression of $\mathrm{N}$-cad-DN in progenitor cells using the ubiquitous CAG promoter disrupts $\alpha$-catenin-positive apical junctions and Nestin-positive radial glia (Jossin and Cooper, 2011). We therefore used a neuronspecific $\mathrm{T} \alpha$-1 promoter-driven $\mathrm{N}$-cad-DN construct. Using in utero electroporation, we transduced the E13.5 cortical VZ with a control $(\mathrm{pT} \alpha-1-\mathrm{LPL})$ or an $\mathrm{N}$-cad-DN-expressing vector (pT $\alpha$-1-LPL-Ncad-DN), together with $\mathrm{pT} \alpha-1$-Cre and $\mathrm{pT} \alpha$-1-LPL-Lyn-EGFP. Three days after electroporation, most control neurons had transited from multipolar to bipolar morphology and migrated into the $\mathrm{CP}$, whereas most $\mathrm{N}$-cad-DN-expressing pyramidal cells failed to acquire bipolar morphology and enter the upper IZ (Fig. 3F-I). Moreover, in the IZ, the N-cad-DN-expressing cells exhibited an abnormal morphology with round soma and extensively elongated leading-like processes (Fig. 3G), most likely due to compromised N-cadherin function. Previous work also showed that electroporated cells expressing T $\alpha$-1 promoterdriven N-cad-DN exhibited migration defects (Kawauchi et al., 2010). Collectively, these findings indicate that an $\mathrm{N}$-cadherin-mediated RGC-pyramidal cell interaction is necessary for pyramidal cells to exit from the multipolar stage.

\section{Rho-Rho-kinase signaling in the cortical neuron is responsible for axon formation at the opposite side from the Nestin-positive cell-contacting neurite}

To determine the mechanism by which the $\mathrm{N}$-cadherin-mediated Nestin-positive cell-cortical neuron interaction directs the location of axon formation, we performed a screening assay for inhibitors that may interfere with signaling cascades involved in the regulation of neuronal polarity (Fig. $4 A$ ). Following $2 \mathrm{~d}$ of coculture of Nestin-positive cells and cortical neurons in the presence of inhibitors at different concentrations, we found that LY294002 (a PI3K inhibitor), U0126 (an MEK inhibitor), SP600125 (a JNK inhibitor), and PP2 (an SFK inhibitor) did not appear to affect the oriented axon formation, whereas Y27632 [a Rho-kinase/ ROCK (Rho-associated, coiled-coil-containing protein kinase) inhibitor] affected axon formation at the opposite side of the cell (Fig. 4B). This result suggests that the oriented axon formation directed by the Nestin-positive cell-cortical neuron interaction may depend on Rho-Rho-kinase signaling but not on PI3K, MEK, JNK, or SFK. To directly examine whether Rho-Rhokinase signaling in cortical neurons is required for the oriented axon formation directed by the Nestin-positive cell-cortical neuron interaction, we inhibited Rho or Rho-kinase activity only in cortical neurons. For this purpose, we used the Rho inhibitor C3 transferase (C3T) and a dominant-negative form of Rho-kinase [Rho-kinase-DN; Rho-kinase-RB/PH (TT); Amano et al., 1999] to inhibit Rho and Rho-kinase activities, respectively. We electroporated dissociated cortical neurons with pEGFP-C1 or pEGFP-C1-C3T in vitro and cocultured the transfected cells with purified Nestin-positive cells for $2 \mathrm{~d}$ (Fig. 4C). As expected, the interaction of Nestin-positive cells with cortical neurons expressing EGFP-C3T failed to direct axon formation opposite of the contacting neurite (Fig. 4D). To effectively inhibit Rho-kinase activity by the overexpression of Rho-kinase-DN in cortical neurons, we electroporated E13.5 embryos with Rho-kinase-DN in vivo, then isolated these primary neurons at E15.5 and cocultured these cells with purified Nestin-positive cells for $2 \mathrm{~d}$ in vitro (Fig. $4 E$ ). Consistent with the results of Y27632 application, the interaction of Nestin-positive cells with cortical neurons expressing Rho-kinase-DN failed to direct the location of axon formation in the cortical neuron (Fig. $4 F$ ). Collectively, our results suggest that Rho-Rho-kinase signaling in cortical neurons is responsible for 
axon formation at the opposite side of the soma from the contacting neurite during the Nestin-positive cell-cortical neuron interaction in vitro.

\section{Nestin-positive cell-cortical neuron interactions induce a polarized distribution of active RhoA at the contact site and active Racl in the opposite neurite}

Some of the major regulators of neuronal polarization include the small Rho GTPases, such as Racl and Cdc42, which act as positive regulators of axon formation, and RhoA, which is a negative regulator of axon formation (Bito et al., 2000; Da Silva et al., 2003; Schwamborn and Püschel, 2004; Nishimura et al., 2005; Garvalov et al., 2007). We therefore hypothesized that the Nestin-positive cell-cortical neuron interaction may localize activated RhoA in the contacting neurite that will not become an axon and localize activated Rac1 and/or Cdc42 in the opposite neurite that will become an axon. To examine the localization of Rho GTPases, we used the wide type of each of these small GTPases and their constitutively active (CA, locked in the GTP-bound state) mutants (RhoACA, V14; Rac1-CA, V12; Cdc42-CA, V12). We coelectroporated dissociated cortical neurons with monomeric red fluorescent protein and EGFP or EGFP-WT (RhoA, Rac1, or Cdc42), or EGFP-CA (RhoA, Rac1, or Cdc42) in vitro, and cocultured these cells with purified Nestin-positive cells for $1 \mathrm{~d}$. At $1 \mathrm{~d}$ in vitro, more than half of the Nestin-positive cellcontacting cortical neurons had reached stage 2, and they typically assumed the characteristic morphology of a contacting neurite like the leading process and an opposite neurite like the trailing process (Fig. 5A). Moreover, the tip of the opposite neurite exhibited a lamellipodial protrusion (Fig. 5A), which is a typical morphology induced by activated Rac1 (Nobes and Hall, 1995). Indeed, EGFPRac1-CA accumulated at the tip of the neurite opposite of the Nestin-positive cell contact site in the cortical neuron, whereas EGFP-RhoA-CA accumulated at the contact site (Fig. 5A,B). In contrast, the EGFP control, EGFP-RhoA-WT, EGFP-Cdc42-WT, CA, and EGFP-Rac1-WT exhibited a uniform distribution (Fig. $5 A, B$ ). The failure of the localization of RhoA-WT and Racl-WT at the specific sites may be due to high RhoGAP activities in neurons, which rapidly inactivate RhoA-WT and Rac1-WT. These results suggest that the Nestinpositive cell-cortical neuron interaction induces polarized distribution of activated RhoA and activated Racl in cortical neuron, thereby directing the location of axon formation to the side opposite of the contacting neurite.
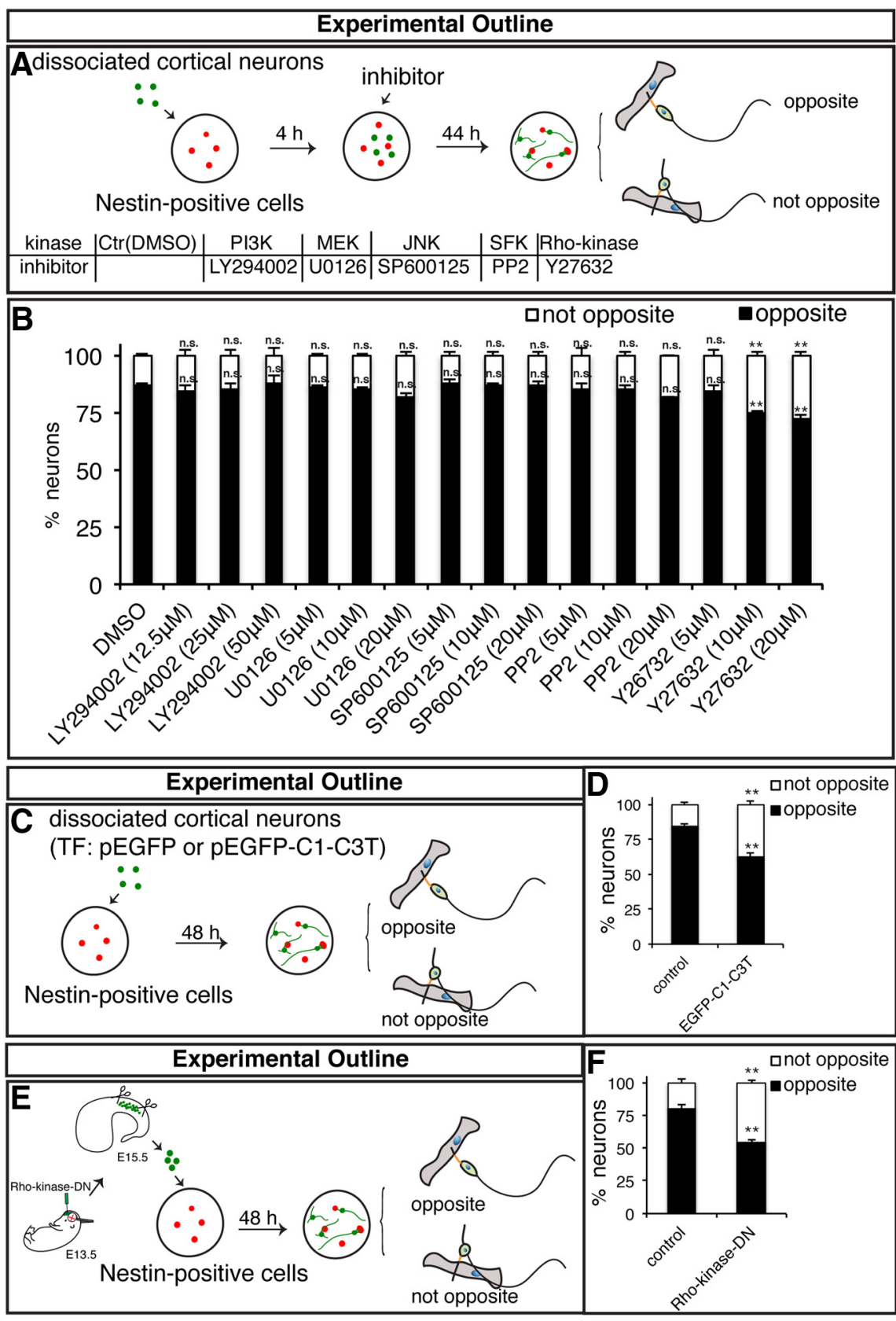

Figure 4. Rho-Rho-kinase signaling in the cortical neuron is required for axon formation at the opposite side from the Nestinpositive cell-contacting neurite. $\boldsymbol{A}$, Schematic of the screening assay for inhibitors. Nestin-positive cells (red) and cortical neurons (green) were cocultured for $4 \mathrm{~h}$, and the cells were subsequently incubated with the indicated inhibitors for 44 h. $\boldsymbol{B}, \boldsymbol{D}, \boldsymbol{F}$, Quantitative analysis of the direction of axon formation under various experimental conditions. ${ }^{* *} p<0.01$, Student's $t$ test. n.S., Not significant. Error bars represent the SEM. $n \geq 40$ Nestin-positive cell-interacting neurons. C, Strategy to perturb the function of Rho in cortical neurons. Dissociated cortical neurons (green) were transfected with the indicated plasmids using in vitro electroporation and cocultured with purified radial glial cells (red) for $48 \mathrm{~h}$. TF, transfect. $\boldsymbol{E}$, Strategy to perturb the function of Rho-kinase in cortical neurons. Cortical neurons (green) were microdissected from E15.5 brains electroporated at E13.5 with the indicated plasmids and subsequently cocultured with purified radial glial cells for $48 \mathrm{~h}$.

Because the functional interaction between Nestin-positive cells and cortical neurons is mediated by N-cadherin (Fig. 2), we reasoned that $\mathrm{N}$-cadherin-mediated adhesion may be responsible for the polarized distribution of activated RhoA and activated Racl in the Nestin-positive cell-contacting cortical neuron. As expected, knockdown of $\mathrm{N}$-cadherin in Nestin-positive cells abrogated the polarized distribution of EGFP-RhoA-CA and EGFP-Racl-CA in Nestin-positive cell-contacting cortical neurons (Fig. 5C-F). Moreover, cor- 

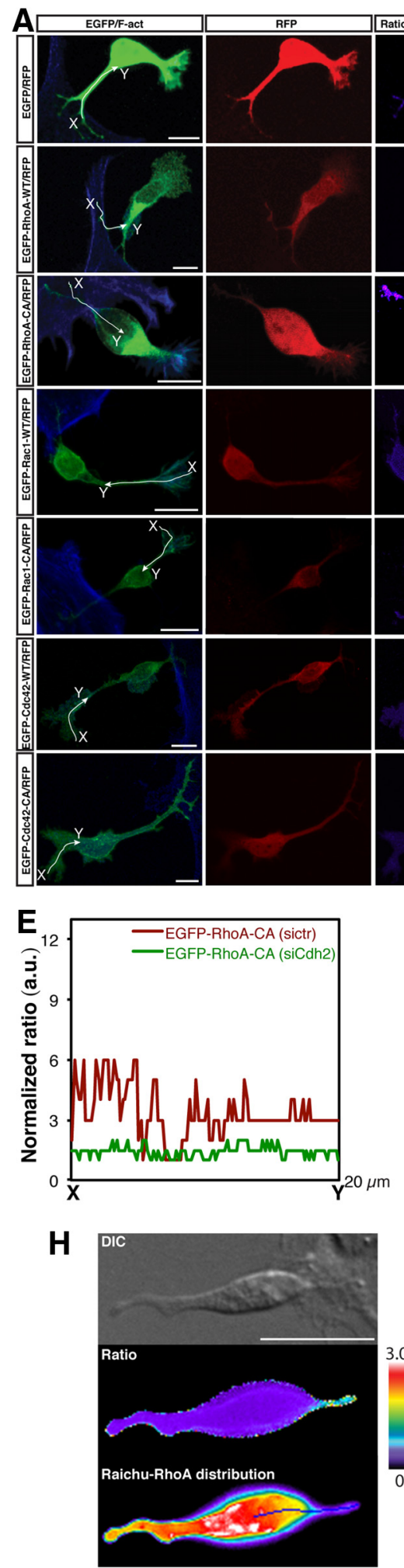

B
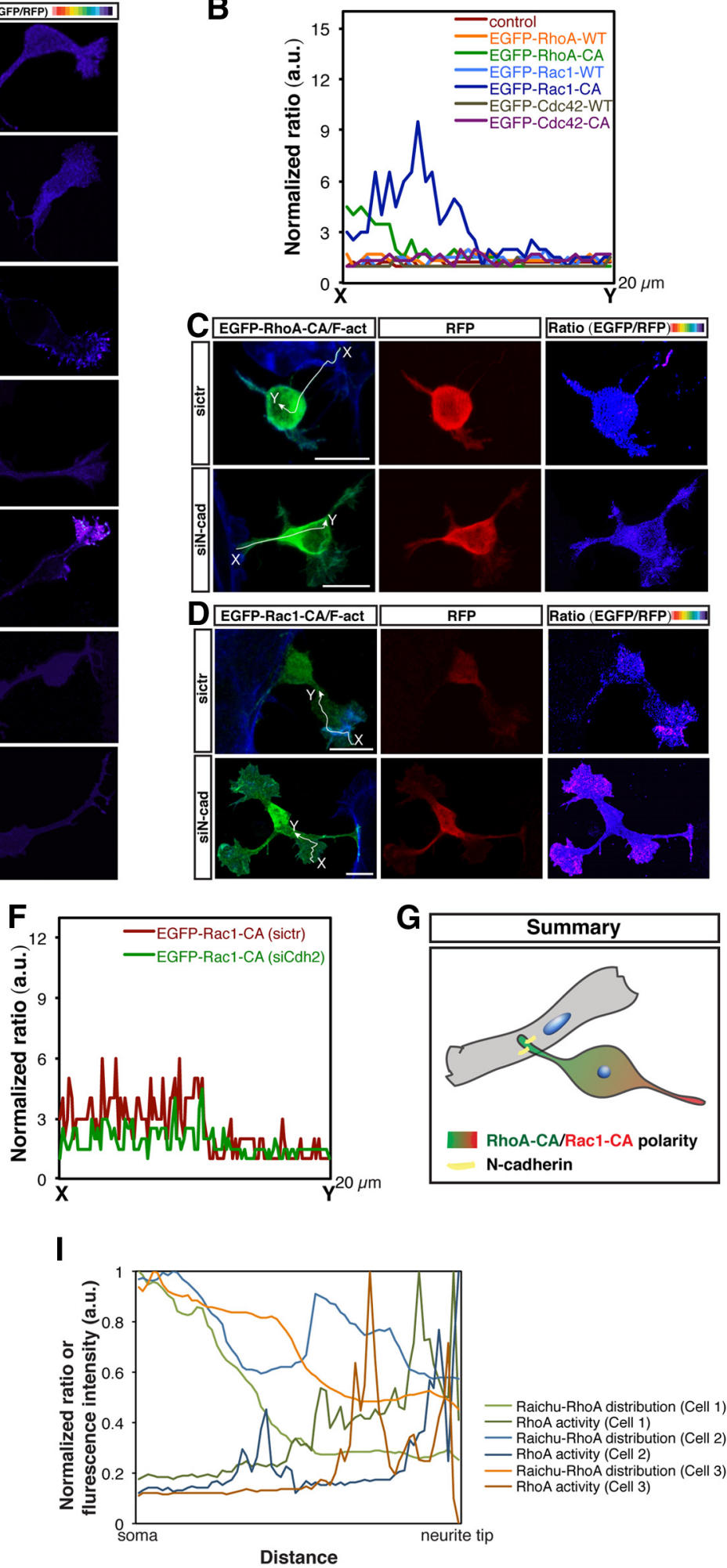

Figure 5. The N-cadherin-dependent Nestin-positive cell-cortical neuron interaction induces polarized distribution of active RhoA at the contact site and active Rac 1 in the opposing neurite. $\boldsymbol{A}$, $\boldsymbol{C}, \boldsymbol{D}$, Representative images of the spatial distributions of RhoA-CA, Rac1-CA, and Cdc42-CA in cultured Nestin-positive cell-contacting cortical neurons under various experimental conditions. $\boldsymbol{A}$, Dissociated cortical neurons were cotransfected with the indicated plasmids using in vitro electroporation and cocultured with purified Nestin-positive cells for $1 \mathrm{~d}$. $\boldsymbol{C}, \boldsymbol{D}$, Purified Nestin-positive cells were transfected with control siRNA or siN-cad $2^{\#}$. One day later, transfected Nestin-positive cells were cocultured with dissociated cortical neurons cotransfected with the indicated plasmids using in vitro electroporation for $1 \mathrm{~d}$. The fluorescence intensity ratio of EGFP to RFP represents the EGFP density normalized by the thickness of the cell and coded with pseudocolors on a linear scale. CA, Constitutively active. Scale bar, $5 \mu \mathrm{m}$. $\boldsymbol{B}, \boldsymbol{E}, \boldsymbol{F}$, Ratio linescans along the line (from $x$ - to $y$-axis) from images in $\boldsymbol{A}, \boldsymbol{C}$, and $\boldsymbol{D}$. G, Summary of the polarized distributions of active RhoA and active Rac1 in N-cadherin-mediated Nestin-positive cell-interacting cortical neuron. $\boldsymbol{H}$, FRET analysis of the distribution of the RhoA activity in cultured Nestin-positive cell-contacting cortical neuron. Scale bar, $10 \mu \mathrm{m}$. $\boldsymbol{I}$, Linescans of the ratio and Raichu-RhoA distribution (normalized to the maximum intensity) in Nestin-positive cell-contacting neurites indicated by the line in $\boldsymbol{H}$. 

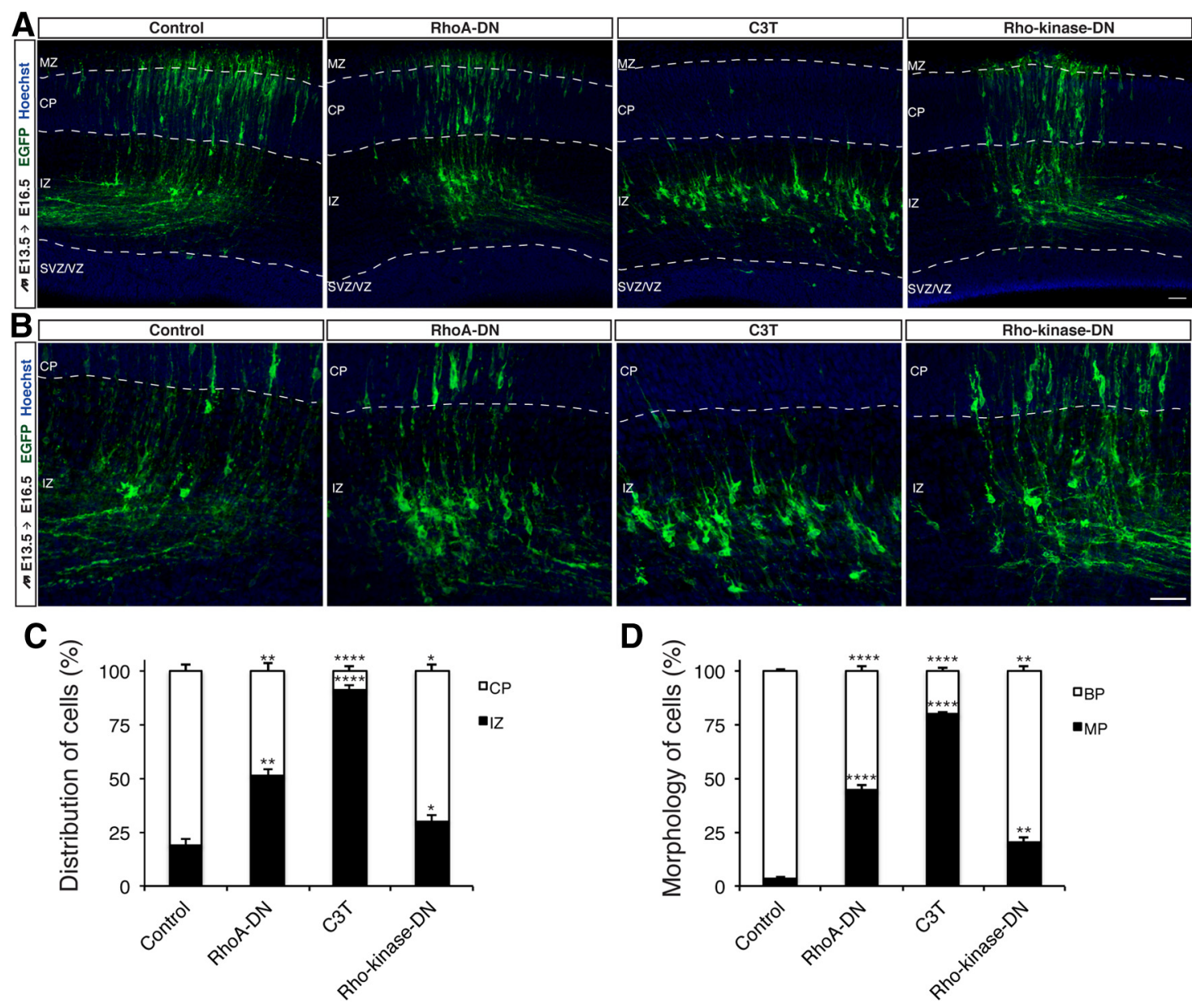

Figure 6. RhoA-Rho-kinase signaling in pyramidal cells is required for MBT. $A, B$, Sections of E16.5 mouse neocortex electroporated with the indicated plasmids plus pT $\alpha$-1-LPL-Lyn-EGFP at E13.5. Scale bar, $50 \mu \mathrm{m}$. C, Quantification of the distribution of electroporated cells from $A$ in distinct regions of the neocortex (CP and IZ). ${ }^{*} p<0.05,{ }^{* *} p<0.01$, ${ }^{* * * *} p<0.0001$, Student's $t$ test. Error bars represent the SEM. D, The percentage of electroporated cells from $A$ with bipolar (BP) or multipolar (MP) morphologies in the neocortex. ${ }^{* *} p<0.01$, ${ }^{* * *} p<0.0001$, Student's $t$ test. Error bars represent the SEM.

tical neurons expressing EGFP-Rac1-CA exhibited wideranging and robust lamellipodial protrusions, which were restricted to the neurites located on the opposite side of the Nestin-positive cell-cortical neuron contact (Fig. $5 A, B$ ). In contrast, lamellipodial protrusions failed to be restricted to one neurite of cortical neurons that contacted Nestin-positive cells expressing siN-cad $2^{\#}$ (Fig. 5D,F). Hence, we conclude that $\mathrm{N}$-cadherin-dependent adhesions are necessary for the polarized distribution of activated RhoA and activated Racl in Nestin-positive cell-contacting cortical neurons (Fig. 5G).

To directly visualize the distribution of RhoA activity in Nestin-positive cell-contacting cortical neurons, we performed FRET analysis using the Raichu-RhoA-CR probe, as previously described (Lam et al., 2012). We cocultured dissociated cortical neurons with purified Nestin-positive cells in vitro for $12 \mathrm{~h}$ and then transfected the cells with Raichu-RhoACR. Eight hours after the transfection, we began FRET analysis. As observed for the distribution of EGFP-RhoA-CA in Nestin-positive cell-contacting cortical neurons, the FRET signal for the active RhoA also exhibited a polarized distribution, with the contacting neurite exhibiting higher activity (Fig. $5 H, I$ ).
RhoA-Rho-kinase signaling in pyramidal cells is required for MBT in vivo

Our previous experiments demonstrated in vitro that during $\mathrm{N}$-cadherin-mediated Nestin-positive cell-cortical neuron interactions, a polarized RhoA activity distribution is required in the contacting neurite for directed axon formation on the opposite side of the cell. We therefore reasoned that RhoA-Rho-kinase signaling in pyramidal cells may be required for MBT in vivo. To evaluate this hypothesis, we evaluated neuronal morphology following the inhibition of RhoA-Rho-kinase signaling in pyramidal cells. Using in utero electroporation, we transduced the E13.5 cortical VZ with a control vector (pT $\alpha$-1-LPL), a RhoADN-expressing vector (pT $\alpha$-1-LPL-RhoA-DN; pT $\alpha$-1-LPLRhoA-N19), a C3T-expressing vector (pT $\alpha$-1-LPL-C3T), or a Rho-kinase-DN-expressing vector [pT $\alpha$-1-LPL-Rho-kinaseDN; pT $\alpha$-1-LPL-Rho-kinase-RB/PH (TT)], together with pT $\alpha$ 1-Cre and pT $\alpha$-1-LPL-Lyn-EGFP. Three days after the electroporation, the majority of the control cells had entered into the $\mathrm{CP}$, whereas most of the C3T-expressing pyramidal cells failed to acquire bipolar morphology and migrate into the upper IZ (Fig. 6A-D). Notably, the C3T-expressing pyramidal cells in the IZ extended elongated leading-like processes (Fig. 6B), likely due to strong inhibition of RhoA activity in the leading-like pro- 


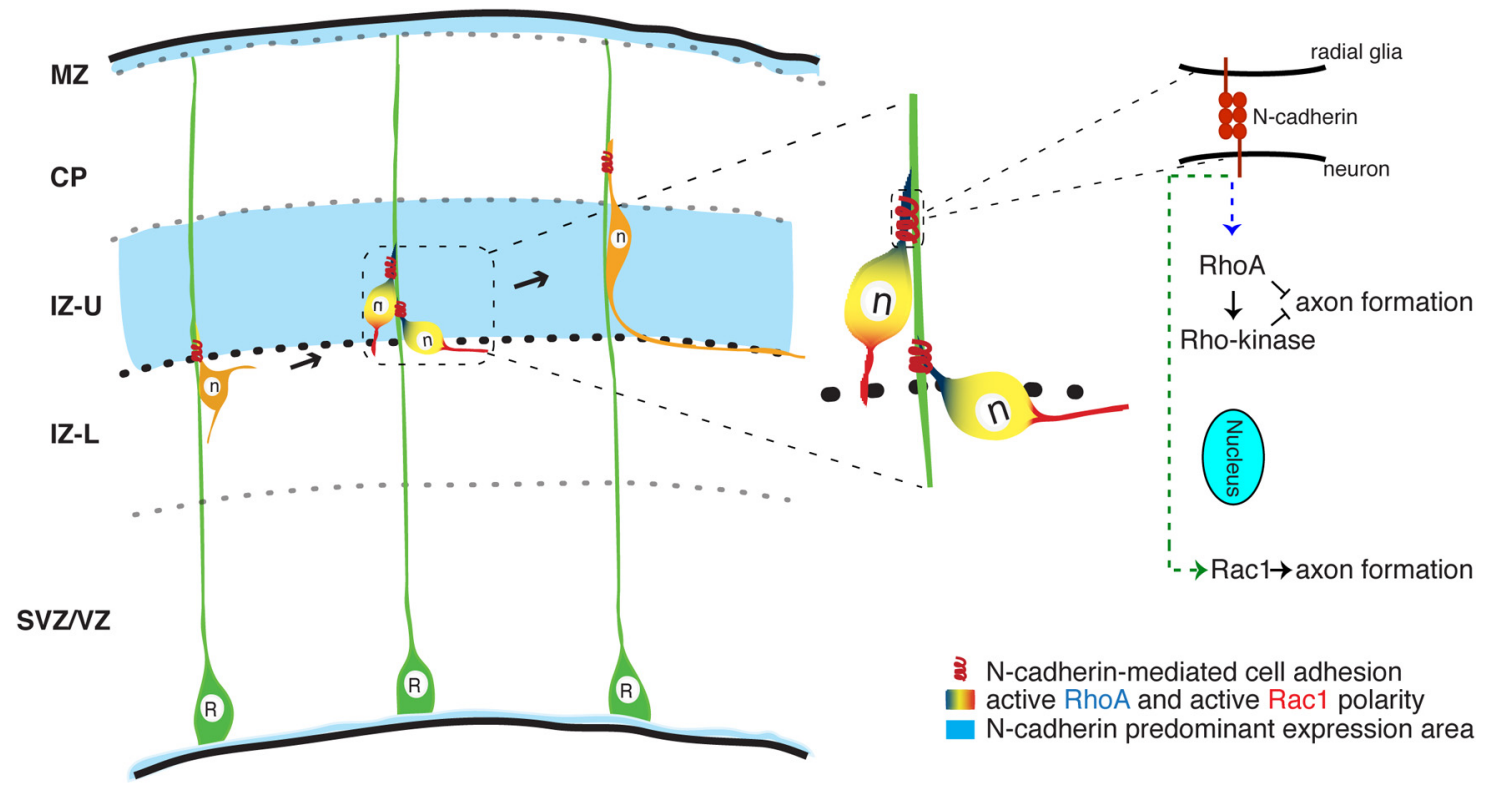

Figure 7. Model depicting the mechanism by which pyramidal cells transit from multipolar to bipolar morphology and establish axon- dendrite polarity. The appearance of bipolar cell notably coincides with the appearance of the predominant expression of N-cadherin in the IZ. In the IZ, the $\mathrm{N}$-cadherin-mediated radial glia-neuron interaction induces a polarized distribution of active Rho $\mathrm{A}$ at the contact site and active Rac1 in the opposing neurite. RhoA-Rho-kinase signaling in the contacting neurite inhibits axon formation; Rac1 in the opposite neurite promotes axon formation. $R$, Radial glial cell; n, neuron.

cess. Similarly, N-cad-DN-expressing pyramidal cells in the IZ also extended elongated leading-like processes, likely due to a lack of activated RhoA in the leading-like process in the absence of $\mathrm{N}$-cadherin function (Fig. $3 \mathrm{H}, 5 \mathrm{C}$ ). In addition, the expression of RhoA-DN in pyramidal cells caused a significant accumulation of cells trapped below the upper IZ with unpolarized morphology and affected neuronal migration (Fig. 6A-D). This defective MBT of pyramidal cells caused by the expression of RhoA-DN was moderate compared with that observed in C3Texpressing pyramidal cells, most likely because RhoA-DN demonstrated a mild inhibitory effect on RhoA activity. Finally, the expression of Rho-kinase-DN in pyramidal cells caused relatively mild defects in cell morphology and migration (Fig. 6A-D), likely due to the presence of molecules in addition to Rho-kinase acting downstream of RhoA during MBT. Collectively, these results suggest that Rho-Rho-kinase signaling in pyramidal cells is required for MBT and the following neuronal migration. A previous article (Pacary et al., 2011) indicated an Ascl1-Rnd3-RhoA signaling pathway promoting neuronal migration through inhibiting RhoA activity. We agree with this finding that RhoA activity needs to be negatively regulated by the Ascl1-Rnd3-RhoA signaling pathway so that RhoA activity will not be too high for neuronal migration. Meanwhile, we think RhoA activity should also not be too low according to our data. Also, the supplemental data in the same article showed that RhoA knockdown in wild-type mouse brain affected neuronal migration in the neocortex and expression of human RhoA (resistant to RhoA shRNA) fully rescued these defects (Pacary et al., 2011), which is consistent with our study. Together, we think our findings on RhoA and the work from Pacary et al. (2011) are not contradictory to each other. And instead, they together indicate that the appropriate level of RhoA activity is vitally important for neuronal polarity and migration, and therefore should be finely regulated. Furthermore, we propose that RhoA activity needs to be spatiotemporally regulated in the neurons.

\section{Discussion}

The establishment of axon-dendrite polarity is critical for neurons to integrate and transmit information in the nervous system. Here, we propose a novel model in which an N-cadherin-mediated RGCpyramidal cell interaction directs the establishment of axon-dendrite polarity. In the IZ, multipolar cells interact with radial glial fibers through $\mathrm{N}$-cadherin. This $\mathrm{N}$-cadherin-mediated interaction subsequently induces a polarized distribution of active RhoA in the contacting neurite and active Racl on the opposite side of the cell, and initiates the transition from multipolar to bipolar cell morphology with the axon forming at the opposite side (Fig. 7).

\section{$\mathrm{N}$-cadherin-mediated RGC-cortical neuron interaction and axon-dendrite polarization}

Our results suggest a novel function for radial glia: polarizing neurons. Due to the bipolar radial morphology exhibited by both neural progenitors and postmitotic neurons, neurons may inherit their axon-dendrite polarity directly from the apico-basal polarity of their progenitors (Barnes et al., 2008; Funahashi et al., 2014). Consistent with this speculation, studies on retinal ganglion cells and bipolar cells have indicated that postmitotic neurons directly inherit the intrinsic apico-basal polarity of their progenitors, which is transformed into axon-dendrite polarity upon cell cycle exit (Hinds and Hinds, 1978; Morgan et al., 2006; Zolessi et al., 2006). However, neuronal differentiation and neuronal migration are not affected when the apical processes of RGCs are severely perturbed in conditional PKC $\lambda$-null mice (Imai et al., 2006). Furthermore, N-cadherin plays an essential role in the initiation and extension of axons from retinal ganglion cells in vivo (Riehl et al., 1996; Esch et al., 2000), which is consistent with our findings. Here, we provide our interpretation that radial glia contribute to the establishment of axon-dendrite neuronal polarity through an $\mathrm{N}$-cadherin-mediated radial glianeuron interaction that directs axon formation to the side of the cortical neuron opposite of the radial glia-contacting neurite and 
maintains the contacting neurite as the leading process for radial glia-guided neuronal migration. In the future, how widely this $\mathrm{N}$-cadherin-mediated radial glia-neuron interaction is applied to establish axon-dendrite polarity in the developing nervous system will be interesting.

\section{Polarized Rho GTPase activity and axon-dendrite polarity}

The subcellular polarity of signaling pathways is essential for multiple cellular functions, such as cell polarization, cell migration, and tissue morphogenesis. We found that N-cadherindependent Nestin-positive cell-cortical neuron interactions induce a polarized distribution of active RhoA at the contact site and active Racl in the opposite neurite, which is consistent with previous studies on the collective migration of Xenopus neural crest cells (Carmona-Fontaine et al., 2008; Theveneau et al., 2010; Rørth, 2011). N-cadherin may activate RhoA in the contacting neurite either by using guanine-nucleotide exchange factors or recruiting activated RhoA to the contacting neurite. Simultaneously, $\mathrm{N}$-cadherin may polarize active Racl in the opposite neurite, presumably due to a lack of active RhoA, because active RhoA can indirectly inhibit Racl activity through the Partitiondefective-3/6 (Par-3/6) complex and Rac GEF T-lymphoma invasion and metastasis-inducing protein-1 (Tiam1) (Nishimura et al., 2005; Nakayama et al., 2008). It may be noted that TAG-1 acts upstream of Lyn and thereby activates Rac1, which may convert the immature neurite to the trailing process in the lower IZ (Namba et al., 2014).

Rho family small GTPases are critical regulators of neuronal polarity (Govek et al., 2005; Arimura and Kaibuchi, 2007; Tahirovic and Bradke, 2009; Gonzalez-Billault et al., 2012). Herein we demonstrate that RhoA-Rho-kinase signaling in Nestin-positive cell-contacting cortical neurons is required for axon formation at the opposite side of the cortical neuron from the contacting neurite. Rho-kinase then may act on several substrates such as myosin light chain (MLC), collapsin response mediator protein 2 (CRMP-2), Tau, and Par-3 (Kimura et al., 1996; Arimura et al., 2000; Amano et al., 2003; Nakayama et al., 2008). Phosphorylation of MLC by Rho-kinase leads to neurite retraction and the inhibition of neurite outgrowth (Amano et al., 1998). Phosphorylation of CRMP-2 and Tau by Rho-kinase inhibits microtubulepolymerizing activity (Amano et al., 2003; Arimura et al., 2005). Phosphorylation of Par-3 by Rho-kinase leads to the dissociation of Par-3 from the Par-6/aPKC complex, likely disrupting the activation of the Rac GEF Tiam1, thereby abrogating Rac1 activation (Nakayama et al., 2008). Therefore, RhoA-Rho-kinase signaling in the Nestin-positive cell-contacting neurite may inhibit the contacting neurite from becoming an axon, whereas Racl in the opposite neurite may promote axon formation, likely due to a lack of RhoA-Rho-kinase signaling (Arimura and Kaibuchi, 2007).

\section{Complementary roles of N-cadherin and TAG-1 in axon formation}

To ensure that the exit from the multipolar stage is spatiotemporally controlled, the expression level and/or subcellular distribution of $\mathrm{N}$-cadherin may be dynamically regulated. Indeed, at E15.5, N-cadherin is prominently expressed in the MZ, the upper IZ, and the luminal surface of the ventricle. The appearance of bipolar cells notably coincides with the appearance of the predominant expression of $\mathrm{N}$-cadherin in the upper IZ. Consistently, a recent study (Ye et al., 2014) reported that Cdk5/ RapGEF2 signaling acts upstream of Rap1/N-cadherin in the upper IZ to promote $\mathrm{MBT}$ and proper neuronal entry into the CP. In this regard, our results may provide insights into the mechanism by which Reelin and Cdk5 engage in the MBT. In contrast to the expression of N-cadherin in the upper IZ, TAG-1 is expressed in the lower IZ, where TAG-1-dependent interactions between multipolar cells $(\sim 60 \%)$ and preexisting axons enable multipolar cells to specify the contacting neurite as an axon and to develop into bipolar cells (Namba et al., 2014). $\mathrm{N}$-cadherin-mediated RGC-neuron interactions then may ensure that the remaining $\sim 40 \%$ of multipolar cells establish axondendrite polarity in the IZ. Therefore, the complementary expression patterns of $\mathrm{N}$-cadherin and TAG-1 in the IZ may provide complementary mechanisms for neuronal polarization in the developing neocortex. The basis of the switch between these two polarity-inducing mechanisms could be cell type specific. Neurons are derived from multiple sources (precursor cells), and therefore they have different gene expression patterns that may contribute to the acquisition of axon-dendrite polarity by cell class-specific neurons in the specific area (TAG-1 band or $\mathrm{N}$-cadherin zone). In the meantime, we could not rule out the possibility that neurons adopt one of these two polarity-inducing mechanisms in a stochastic way.

The current model for axon specification is that the polarized emergence of a single axon is controlled at least in part by extracellular cues, such as TGF- $\beta$, neurotrophins, and Semaphorin $3 \mathrm{~A}$, which are expressed in a graded manner along the migratory path of the neuron (Polleux and Snider, 2010; Yi et al., 2010; Shelly et al., 2011). This model may account for axon formation of cortical neurons toward the VZ, but not for the precise control of when and where to specify a single axon. We have recently found that multipolar cells extend the trailing process omnidirectionally at the early stage and then migrate toward the $\mathrm{CP}$, leaving the trailing process behind the soma and resulting in axon formation toward the VZ (Namba et al., 2014). Our findings suggest a novel model in which the TAG-1-mediated interaction between the immature neurite and the pioneering axons directs axon formation in the lower IZ, and the N-cadherin-mediated RGC-neuron interaction directs the axon-dendrite polarity in the upper IZ. The gradient of extracellular factors may aid in the directional migration of the cortical neurons along the radial glial fibers and axon elongation, but may not directly determine the axon initiation.

\section{References}

Amano M, Chihara K, Nakamura N, Fukata Y, Yano T, Shibata M, Ikebe M, Kaibuchi K (1998) Myosin II activation promotes neurite retraction during the action of Rho and Rho-kinase. Genes Cells 3:177-188. CrossRef Medline

Amano M, Chihara K, Nakamura N, Kaneko T, Matsuura Y, Kaibuchi K (1999) The COOH terminus of Rho-kinase negatively regulates rhokinase activity. J Biol Chem 274:32418-32424. CrossRef Medline

Amano M, Kaneko T, Maeda A, Nakayama M, Ito M, Yamauchi T, Goto H, Fukata Y, Oshiro N, Shinohara A, Iwamatsu A, Kaibuchi K (2003) Identification of Tau and MAP2 as novel substrates of Rho-kinase and myosin phosphatase. J Neurochem 87:780-790. CrossRef Medline

Arimura N, Kaibuchi K (2007) Neuronal polarity: from extracellular signals to intracellular mechanisms. Nat Rev Neurosci 8:194-205. CrossRef Medline

Arimura N, Inagaki N, Chihara K, Menager C, Nakamura N, Amano M, Iwamatsu A, Goshima Y, Kaibuchi K (2000) Phosphorylation of collapsin response mediator protein-2 by Rho-kinase. Evidence for two separate signaling pathways for growth cone collapse. J Biol Chem 275:2397323980. CrossRef Medline

Arimura N, Menager C, Kawano Y, Yoshimura T, Kawabata S, Hattori A, Fukata Y, Amano M, Goshima Y, Inagaki M, Morone N, Usukura J, Kaibuchi K (2005) Phosphorylation by Rho kinase regulates CRMP-2 activity in growth cones. Mol Cell Biol 25:9973-9984. CrossRef Medline 
Barnes AP, Solecki D, Polleux F (2008) New insights into the molecular mechanisms specifying neuronal polarity in vivo. Curr Opin Neurobiol 18:44-52. CrossRef Medline

Bielas S, Higginbotham H, Koizumi H, Tanaka T, Gleeson JG (2004) Cortical neuronal migration mutants suggest separate but intersecting pathways. Annu Rev Cell Dev Biol 20:593-618. CrossRef Medline

Bito H, Furuyashiki T, Ishihara H, Shibasaki Y, Ohashi K, Mizuno K, Maekawa M, Ishizaki T, Narumiya S (2000) A critical role for a Rhoassociated kinase, p160ROCK, in determining axon outgrowth in mammalian CNS neurons. Neuron 26:431-441. CrossRef Medline

Carmona-Fontaine C, Matthews HK, Kuriyama S, Moreno M, Dunn GA, Parsons M, Stern CD, Mayor R (2008) Contact inhibition of locomotion in vivo controls neural crest directional migration. Nature 456: 957-961. CrossRef Medline

Da Silva JS, Medina M, Zuliani C, Di Nardo A, Witke W, Dotti CG (2003) RhoA/ROCK regulation of neuritogenesis via profilin IIa-mediated control of actin stability. J Cell Biol 162:1267-1279. CrossRef Medline

Esch T, Lemmon V, Banker G (2000) Differential effects of NgCAM and $\mathrm{N}$-cadherin on the development of axons and dendrites by cultured hippocampal neurons. J Neurocytol 29:215-223. CrossRef Medline

Etienne-Manneville S (2011) Control of polarized cell morphology and motility by adherens junctions. Semin Cell Dev Biol 22:850-857. CrossRef Medline

Funahashi Y, Namba T, Fujisue S, Itoh N, Nakamuta S, Kato K, Shimada A, Xu C, Shan W, Nishioka T, Kaibuchi K (2013) ERK2-mediated phosphorylation of Par3 regulates neuronal polarization. J Neurosci 33: 13270-13285. CrossRef Medline

Funahashi Y, Namba T, Nakamuta S, Kaibuchi K (2014) Neuronal polarization in vivo: growing in a complex environment. Curr Opin Neurobiol 27:215-223. CrossRef Medline

Garvalov BK, Flynn KC, Neukirchen D, Meyn L, Teusch N, Wu X, Brakebusch C, Bamburg JR, Bradke F (2007) Cdc42 regulates cofilin during the establishment of neuronal polarity. J Neurosci 27:13117-13129. CrossRef Medline

Gongidi V, Ring C, Moody M, Brekken R, Sage EH, Rakic P, Anton ES (2004) SPARC-like 1 Regulates the terminal phase of radial glia-guided migration in the cerebral cortex. Neuron 41:57-69. CrossRef Medline

Gonzalez-Billault C, Munoz-Llancao P, Henriquez DR, Wojnacki J, Conde C, Caceres A (2012) The role of small GTPases in neuronal morphogenesis and polarity. Cytoskeleton 69:464-485. CrossRef Medline

Götz M, Huttner WB (2005) The cell biology of neurogenesis. Nat Rev Mol Cell Biol 6:777-788. CrossRef Medline

Govek EE, Newey SE, Van Aelst L (2005) The role of the Rho GTPases in neuronal development. Genes Dev 19:1-49. Medline 10.1101/gad.1256405

Govek EE, Hatten ME, Van Aelst L (2011) The role of Rho GTPase proteins in CNS neuronal migration. Dev Neurobiol 71:528-553. CrossRef Medline

Halbleib JM, Nelson WJ (2006) Cadherins in development: cell adhesion, sorting, and tissue morphogenesis. Genes Dev 20:3199-3214. CrossRef Medline

Hatanaka Y, Murakami F (2002) In vitro analysis of the origin, migratory behavior, and maturation of cortical pyramidal cells. J Comp Neurol 454:1-14. CrossRef Medline

Heuberger J, Birchmeier W (2010) Interplay of cadherin-mediated cell adhesion and canonical Wnt signaling. Cold Spring Harb Perspect Biol 2:a002915. CrossRef Medline

Hinds JW, Hinds PL (1978) Early development of amacrine cells in the mouse retina: an electron microscopic, serial section analysis. J Comp Neurol 179:277-300. CrossRef Medline

Imai F, Hirai S, Akimoto K, Koyama H, Miyata T, Ogawa M, Noguchi S, Sasaoka T, Noda T, Ohno S (2006) Inactivation of aPKClambda results in the loss of adherens junctions in neuroepithelial cells without affecting neurogenesis in mouse neocortex. Development 133:1735-1744. CrossRef Medline

Jossin Y, Cooper JA (2011) Reelin, Rap1 and N-cadherin orient the migration of multipolar neurons in the developing neocortex. Nat Neurosci 14:697-703. CrossRef Medline

Kawauchi T, Chihama K, Nabeshima Y, Hoshino M (2003) The in vivo roles of STEF/Tiam1, Racl and JNK in cortical neuronal migration. EMBO J 22:4190-4201. CrossRef Medline

Kawauchi T, Sekine K, Shikanai M, Chihama K, Tomita K, Kubo K, Nakajima K, Nabeshima Y, Hoshino M (2010) Rab GTPases-dependent endocy- tic pathways regulate neuronal migration and maturation through $\mathrm{N}$-cadherin trafficking. Neuron 67:588-602. CrossRef Medline

Kimura K, Ito M, Amano M, Chihara K, Fukata Y, Nakafuku M, Yamamori B, Feng J, Nakano T, Okawa K, Iwamatsu A, Kaibuchi K (1996) Regulation of myosin phosphatase by Rho and Rho-associated kinase (Rho-kinase). Science 273:245-248. CrossRef Medline

Lam AJ, St-Pierre F, Gong Y, Marshall JD, Cranfill PJ, Baird MA, McKeown MR, Wiedenmann J, Davidson MW, Schnitzer MJ, Tsien RY, Lin MZ (2012) Improving FRET dynamic range with bright green and red fluorescent proteins. Nat Methods 9:1005-1012. CrossRef Medline

LoTurco JJ, Bai J (2006) The multipolar stage and disruptions in neuronal migration. Trends Neurosci 29:407-413. CrossRef Medline

Miyata T, Kawaguchi A, Okano H, Ogawa M (2001) Asymmetric inheritance of radial glial fibers by cortical neurons. Neuron 31:727-741. CrossRef Medline

Morgan JL, Dhingra A, Vardi N, Wong RO (2006) Axons and dendrites originate from neuroepithelial-like processes of retinal bipolar cells. Nat Neurosci 9:85-92. CrossRef Medline

Nakamuta S, Funahashi Y, Namba T, Arimura N, Picciotto MR, Tokumitsu H, Soderling TR, Sakakibara A, Miyata T, Kamiguchi H, Kaibuchi K (2011) Local application of neurotrophins specifies axons through inositol 1,4,5-trisphosphate, calcium, and $\mathrm{Ca} 2+/$ calmodulin-dependent protein kinases. Sci Signal 4:ra76. CrossRef Medline

Nakayama M, Goto TM, Sugimoto M, Nishimura T, Shinagawa T, Ohno S, Amano M, Kaibuchi K (2008) Rho-kinase phosphorylates PAR-3 and disrupts PAR complex formation. Dev Cell 14:205-215. CrossRef Medline

Namba T, Kibe Y, Funahashi Y, Nakamuta S, Takano T, Ueno T, Shimada A, Kozawa S, Okamoto M, Shimoda Y, Oda K, Wada Y, Masuda T, Sakakibara A, Igarashi M, Miyata T, Faivre-Sarrailh C, Takeuchi K, Kaibuchi K (2014) Pioneering axons regulate neuronal polarization in the developing cerebral cortex. Neuron 81:814-829. CrossRef Medline

Nichols AJ, Carney LH, Olson EC (2008) Comparison of slow and fast neocortical neuron migration using a new in vitro model. BMC Neurosci 9:50. CrossRef Medline

Nishimura T, Yamaguchi T, Kato K, Yoshizawa M, Nabeshima Y, Ohno S, Hoshino M, Kaibuchi K (2005) PAR-6-PAR-3 mediates Cdc42-induced Rac activation through the Rac GEFs STEF/Tiam1. Nat Cell Biol 7:270277. CrossRef Medline

Nobes CD, Hall A (1995) Rho, rac, and cdc42 GTPases regulate the assembly of multimolecular focal complexes associated with actin stress fibers, lamellipodia, and filopodia. Cell 81:53-62. CrossRef Medline

Noctor SC, Flint AC, Weissman TA, Dammerman RS, Kriegstein AR (2001) Neurons derived from radial glial cells establish radial units in neocortex. Nature 409:714-720. CrossRef Medline

Noctor SC, Martínez-Cerdeño V, Ivic L, Kriegstein AR (2004) Cortical neurons arise in symmetric and asymmetric division zones and migrate through specific phases. Nat Neurosci 7:136-144. CrossRef Medline

Pacary E, Heng J, Azzarelli R, Riou P, Castro D, Lebel-Potter M, Parras C, Bell DM, Ridley AJ, Parsons M, Guillemot F (2011) Proneural transcription factors regulate different steps of cortical neuron migration through Rndmediated inhibition of RhoA signaling. Neuron 69:1069-1084. CrossRef Medline

Polleux F, Snider W (2010) Initiating and growing an axon. Cold Spring Harb Perspect Biol 2:a001925. CrossRef Medline

Reiner O, Sapir T (2009) Polarity regulation in migrating neurons in the cortex. Mol Neurobiol 40:1-14. CrossRef Medline

Riehl R, Johnson K, Bradley R, Grunwald GB, Cornel E, Lilienbaum A, Holt CE (1996) Cadherin function is required for axon outgrowth in retinal ganglion cells in vivo. Neuron 17:837-848. CrossRef Medline

Rørth P (2011) Whence directionality: guidance mechanisms in solitary and collective cell migration. Dev Cell 20:9-18. CrossRef Medline

Sakakibara A, Sato T, Ando R, Noguchi N, Masaoka M, Miyata T (2014) Dynamics of centrosome translocation and microtubule organization in neocortical neurons during distinct modes of polarization. Cereb Cortex 24:1301-1310. CrossRef Medline

Schwamborn JC, Püschel AW (2004) The sequential activity of the GTPases Rap1B and Cdc42 determines neuronal polarity. Nat Neurosci 7:923-929. CrossRef Medline

Shelly M, Cancedda L, Lim BK, Popescu AT, Cheng PL, Gao H, Poo MM (2011) Semaphorin3A regulates neuronal polarization by suppressing 
axon formation and promoting dendrite growth. Neuron 71:433-446. CrossRef Medline

Tabata H, Nakajima K (2003) Multipolar migration: the third mode of radial neuronal migration in the developing cerebral cortex. J Neurosci 23:9996-10001. Medline

Tabdili H, Barry AK, Langer MD, Chien YH, Shi Q, Lee KJ, Lu S, Leckband DE (2012) Cadherin point mutations alter cell sorting and modulate GTPase signaling. J Cell Sci 125:3299-3309. CrossRef Medline

Tahirovic S, Bradke F (2009) Neuronal polarity. Cold Spring Harb Perspect Biol 1:a001644. CrossRef Medline

Tamura K, Shan WS, Hendrickson WA, Colman DR, Shapiro L (1998) Structure-function analysis of cell adhesion by neural $(\mathrm{N}-)$ cadherin. Neuron 20:1153-1163. CrossRef Medline

Taverna E, Götz M, Huttner WB (2014) The cell biology of neurogenesis: toward an understanding of the development and evolution of the neocortex. Annu Rev Cell Dev Biol 30:465-502. CrossRef Medline

Theveneau E, Marchant L, Kuriyama S, Gull M, Moepps B, Parsons M, Mayor R (2010) Collective chemotaxis requires contact-dependent cell polarity. Dev Cell 19:39-53. CrossRef Medline

Ye T, Ip JP, Fu AK, Ip NY (2014) Cdk5-mediated phosphorylation of RapGEF2 controls neuronal migration in the developing cerebral cortex. Nat Commun 5:4826. CrossRef Medline

Yi JJ, Barnes AP, Hand R, Polleux F, Ehlers MD (2010) TGF-beta signaling specifies axons during brain development. Cell 142:144-157. CrossRef Medline

Zolessi FR, Poggi L, Wilkinson CJ, Chien CB, Harris WA (2006) Polarization and orientation of retinal ganglion cells in vivo. Neural Dev 1:2. CrossRef Medline 